This work is on a Creative Commons Attribution 4.0 International (CC DY 4.0) license, https://creativecommons.org/licenses/by/4.0/. Access to this work was provided by the University of Maryland, Baltimore County (UMBC) ScholarWorks@UMBC digital repository on the Maryland Shared Open Access (MD-SOAR) platform.

Please provide feedback

Please support the ScholarWorks@UMBC repository by emailing scholarworks-group@umbc.edu and telling us what having access to this work means to you and why it's important to you. Thank you. 


\section{Evaluation of climate model aerosol trends with ground-based observations over the last two decades - an AeroCom and CMIP6 analysis}

Augustin Mortier ${ }^{1}$, Jonas Gliss ${ }^{1}$, Michael Schulz ${ }^{1}$, Wenche Aas ${ }^{2}$, Elisabeth Andrews ${ }^{3}$, Huisheng Bian ${ }^{4}$, Mian Chin ${ }^{5}$, Paul Ginoux ${ }^{6}$, Jenny Hand ${ }^{7}$, Brent Holben ${ }^{5}$, Zhang Hua $^{8}$, Zak Kipling ${ }^{9}$, Alf Kirkevåg ${ }^{1}$, Paolo Laj ${ }^{10}$, Thibault Lurton ${ }^{11}$, Gunnar Myhre ${ }^{12}$, David Neubauer ${ }^{13}$, Dirk Olivié ${ }^{1}$, Knut von Salzen ${ }^{14}$, Toshihiko Takemura ${ }^{15}$, and Simone Tilmes ${ }^{16}$

${ }^{1}$ Norwegian Meteorological Institute, Oslo, Norway

${ }^{2}$ NILU, Norwegian Institute for Air Research, Kjeller, Norway

${ }^{3}$ Cooperative Institute for Research in Environmental Sciences, University of Colorado, Boulder, Colorado, USA

${ }^{4}$ Maryland Univ. Baltimore County (UMBC), Baltimore, MD, USA

${ }^{5}$ NASA Goddard Space Flight Center, Greenbelt, Maryland, USA

${ }^{6}$ NOAA, Geophysical Fluid Dynamics Laboratory, Princeton, NJ, USA

${ }^{7}$ Cooperative Institute for Research in the Atmosphere, Colorado State University, Fort Collins, CO, USA

${ }^{8}$ Laboratory for Climate Studies, National Climate Center, China Meteorological Administration, Beijing, China

${ }^{9}$ European Centre for Medium-Range Weather Forecasts, Reading, UK

${ }^{10}$ Univ. Grenoble Alpes, CNRS, IRD, Grenoble INP, Institute for Geosciences and Environmental Research, Grenoble, France

${ }^{11}$ Met Office Hadley Centre, Exeter, UK

${ }^{12}$ CICERO Center for International Climate and Environmental Research, Oslo, Norway

${ }^{13}$ Institute for Atmospheric and Climate Science, ETH Zurich, Zurich, Switzerland

${ }^{14}$ Environment Canada, Montréal, Canada

${ }^{15}$ Research Institute for Applied Mechanics, Kyushu University, 6-1 Kasuga-koen, Kasuga, Fukuoka, Japan

${ }^{16}$ National Center for Atmospheric Research (NCAR), Boulder, Colorado, USA

Correspondence: Augustin Mortier (augustinm@met.no)

Abstract. This study presents a multi-parameter analysis of aerosol trends over the last two decades at regional and global scales. Regional time series have been computed for a set of nine optical, chemical composition and mass aerosol properties by using the observations of several ground-based networks. From these regional time series the aerosol trends have been derived for different regions of the world. Most of the properties related to aerosol loading exhibit negative trends, both at the surface and in the total atmospheric column. Significant decreases of aerosol optical depth (AOD) are found in Europe, North America, South America and North Africa, ranging from $-1.3 \% / \mathrm{yr}$ to $-3.1 \% / \mathrm{yr}$. An error and representativity analysis of the incomplete observational data has been performed using model data subsets in order to investigate how likely the observed trends represent the actual trends happening in the regions over the full study period from 2000 to 2014. This analysis reveals that significant uncertainty is associated with some of the regional trends due to time and space sampling deficiencies. The set of observed regional trends has then been used for the evaluation of the climate models and their skills in reproducing the aerosol trends. Model performance is found to vary depending on the parameters and the regions of the world. The models tend to capture trends in AOD, column Angstrom exponent, sulfate and particulate matter well (except in North Africa), but 
show larger discrepancies for coarse mode AOD. The rather good agreement of the trends, across different aerosol parameters between models and observations, when co-locating them in time and space, implies that global model trends, including those in poorly monitored regions, are likely correct. The models can help to provide a global picture of the aerosol trends by filling the gaps in regions not covered by observations. The calculation of aerosol trends at a global scale reveals a different picture from the one depicted by solely relying on ground based observations. Using a model with complete diagnostics (NorESM2) we find a global increase of AOD of about $0.2 \%$ yr between 2000 and 2014, primarily caused by an increase of the loads of organic aerosol, sulfate and black carbon.

\section{Introduction}

As one of the key gears involved in the climate mechanism (Pöschl, 2005), and as a predominant component of air quality that affects human health (Burnett et al., 2014), aerosols have been increasingly subject to observation over the last two decades, both from ground and space-based platforms (Holben et al., 2001; Kaufman et al., 2002). Aerosols are also recognized to have an important role for the fertilization of the Amazon forest (Yu et al., 2015), and in other socioeconomic fields such as the solar energy production (Li et al., 2017; Labordena et al., 2018).

Through their direct, semi-direct and indirect effects (Rap et al., 2013; Johnson et al., 2004; Lohmann and Feichter, 2005), aerosol particles are crucial for the estimation of the radiative forcing. Currently, the overall estimate of aerosol radiative forcing is associated with high uncertainties (Haywood and Boucher, 2000; Stocker, 2014). Some of the reasons for these uncertainties reside in the heterogeneity of atmospheric particles, both in terms of their microphysical and optical properties, as well as the high variability of these aerosols in space and time. The different regions of the world exhibit contrasting aerosol properties (Holben et al., 2001), which can vary depending on the seasons, from year to year, and possibly exhibit inter-annual trends (Streets et al., 2009). In addition to natural emissions such as sea salt and dust, anthropogenic sources of aerosol add another layer of complexity. The Second Industrial Revolution, which relied on the use of fossil fuel energy, has had a significant impact on the aerosol load on a global scale, and on the local air quality, resulting in severe pollution episodes, such as the famous smog event in London, 1952 (Bell et al., 2004) that caused the death of thousands of people within a few days. Starting in the 1970s in the US, and in the 1990s in Europe, mitigation measures were established to limit the emission of particles and other pollutants (Bryner, 1995; Turnock et al., 2016) resulting in significant improvements in terms of air quality and particle concentration levels (Likens et al., 2001). In recent decades there has been a shift of anthropogenic emissions from Europe and North America to the developing nations, which are now facing, in varying degrees, the air quality issues that affected Europe and North America 40 years ago (Streets et al., 2008; Ramachandran et al., 2012).

In order to provide realistic radiative forcing estimates and projections, it is important for the models to be able to capture the aerosol trends caused by both natural and anthropogenic variations. With a consistent multi-parameter analysis, this study 
presents an overview of aerosol trends using ground based observation network data as a reference for the evaluation of the models skills in reproducing the aerosols trends.

To serve that purpose, this study addresses the following three questions:

- What are the observed aerosol trends over the last two decades in the different regions of the world? (Section 4.1)

- Can the climate models reproduce these observed trends? (Section 4.2)

- What are the global aerosol trends derived from the model data? (Section 4.3)

Figure 1 presents the time series of global modeled AOD between 1850 and 2014. All of the climate models appear to exhibit a large increase in AOD, especially between 1950 and 1990, followed by more stable conditions up to the present. While the models show some diversity in absolute values, the trends (focus of this paper) seem to be consistent, among the different models, at a global scale. The aerosol optical measurements, which started to develop in the late 1990's, allow investigation of the trends over the last two decades, and offer an opportunity to validate the modeled trends in this period. Since 2014 is the last year available from the CMIP6 historical runs, we focus this study on the aerosol trends in the 2000-2014 period.

\section{Datasets}

A set of nine column and in situ surface aerosol datasets are used in this study. The observation networks and the models providing output for these parameters are reported in Table 1.

\subsection{Observations}

60 For each of the parameters used in this study, data of the highest quality level provided by the different observation networks were used. Mountain sites, corresponding to an elevation above $1000 \mathrm{~m}$, were excluded, mainly because global models have problems to simulate the aerosol distribution in steep terrain (Kinne et al., 2013).

\subsubsection{Columnar aerosol optical properties}

The AErosol RObotic NETwork (AERONET) is a network established by NASA (National Aeronautics and Space Administration), and expanded by national and international collaborations. AERONET operates aerosol ground-based measurements in the different regions of the world (Holben et al., 2001). The observation of the columnar aerosol properties is performed by standardized and calibrated solar-powered CIMEL Electronique sunphotometers. These instruments measure the solar radiation reaching the surface of the Earth at different wavelengths and for different optical geometries. A new version of the sunphotometer (CE318-T) is also able to perform night-time measurements using the moon as light-source (Barreto et al., 2016). The direct measurements (aiming at the light-source) allow for the derivation of the aerosol optical depth (AOD), and the Angstrom exponent (AE) which are related to the amount and size of the particles, respectively. The spectral information can be further utilized to derive the AOD for the fine and the coarse particles, split by diameter less than or greater than $1 \mu \mathrm{m}$ 
(O'neill et al., 2003). Three different data quality levels are available depending on the application of cloud filtering and correction for instruments calibration derivations (Smirnov et al., 2000, 2004). The level 2.0 version 3 daily data, which provides automatic instrument anomaly quality controls (Giles et al., 2019), are used in this study for four different parameters: AOD (calculated at $550 \mathrm{~nm}$ ), AE (calculated using $440 \mathrm{~nm}$ and $870 \mathrm{~nm}$ channels), AOD $<1 \mu \mathrm{m}$ (or fine AOD), and AOD $>1 \mu \mathrm{m}$ (or coarse AOD) corresponding to the AOD of the particles whose diameter is less than and greater than $1 \mu \mathrm{m}$, respectively.

\subsubsection{Particulate matter concentrations}

The particulate matter (PM) measurements are from EMEP (covering Europe), and IMPROVE (for North America). The PM data have been made available either via the EBAS database infrastructure (http://ebas.nilu.no), or in the original IMPROVE data to be found in the VIEWS database (http://views.cira.colostate.edu/). Both $\mathrm{PM}_{10}$ and $\mathrm{PM}_{2.5}$ (with unit $\mu \mathrm{g} . \mathrm{m}^{-3}$ ) are used in this study. Note that the $\mathrm{PM}_{10}$ size fraction of particles below $10 \mu \mathrm{m}$ encompasses the $\mathrm{PM}_{2.5}$ aerosol mass below $2.5 \mu \mathrm{m}$.

The first PM measurements in EMEP started in 1996 and the number of sites increased steadily in the following decade (Tørseth et al., 2012). Most of the sites use the gravimetric method for both size fractions, though some used automated monitors, i.e. TEOM FDMS or b-attenuation. The EMEP monitoring complies with the European standards, i.e EN12341:2014 for the gravimetric methods and EN16450:2017 for the automatic methods.

The IMPROVE network has been operating since 1988 at remote and rural sites across the United States. IMPROVE uses four separate modules to collect samples for speciated $\mathrm{PM}_{2.5}$ analysis and gravimetric $\mathrm{PM}_{2.5}$ and $\mathrm{PM}_{10}$ bulk mass measurements. Samples are collected every third day for $24 \mathrm{~h}$ and reported at local conditions. $\mathrm{PM}_{2.5}$ and $\mathrm{PM}_{10}$ mass concentrations are determined from Teflon filters from two separate modules sampling with $\mathrm{PM}_{2.5}$ and $\mathrm{PM}_{10}$ inlets, respectively. The gravimetric mass measurements are not performed at controlled relative humidity and temperature, and a laboratory relocation in 2011 resulted in unstable weighing conditions. Therefore, gravimetric mass measurements from 2011-2018 were subject to potentially high relative humidity conditions and likely contain particle bound water on the filters that could bias trends (Hand et al., 2019).

\subsection{3 $\mathrm{SO}_{4}$ air concentration}

The sulphate aerosol concentration dataset is a subset of the global data presented in Aas et al. (2019) and is based on measurements obtained in different regional networks as described in Table 1. The sulfate aerosol concentrations are obtained from analysis of aerosol filters. In the EMEP, CASTNET, CAPMON and EANET networks these are either sampled with a $\mathrm{PM}_{10}$ inlet or a total aerosol inlet, with no specific size cut off effective, using a filterpack sampler In the IMPROVE network sulfate measurements are done using a filterpack sampler with a $\mathrm{PM}_{2.5}$ inlet. The filters are typically analysed by ion chromatography after water extraction of the aerosol filter.

The data have been screened to be regionally representative and of satisfactory quality. Urban sites are not included, nor are sites where the surroundings have changed considerably in the period in question. In Aas et al. (2019) the data were averaged to monthly means. When the data have lower sampling frequency than daily, samples are weighted prior to averaging in accordance with how many days were sampled in a given month. 


\subsubsection{Scattering and absorption coefficients}

Due to the scarcity of stations available for long-term trend analysis (only 28), the presence of regionally non-representative stations (e.g., stations located near roads, in cities), difficult to capture by global models, can have large effects on the computation of the regional average time series. The urban stations have therefore been removed from this analysis. The level 2 data (quality controlled, hourly averaged, reported at standard temperature and pressure conditions) were used for two parameters measured by different instruments:

- Scattering coefficients $\left(\sigma_{s p}\right.$, in $\mathrm{Mm}^{-1}$ ), were measured by integrating nephelometers. For better consistency in the model comparisons (model data for these parameters are reported for $\mathrm{RH}=0 \%$ ), only the measurement data obtained when the relative humidity in the instrument was lower than $40 \%$ were utilized (Pandolfi et al., 2018).

- Absorption coefficients $\left(\sigma_{a p}\right.$, in $\left.\mathrm{Mm}^{-1}\right)$, were obtained from filter-based absorption photometers.

Altogether the same data selection procedures (exclusion of stations, removal of outliers) and corrections (conversion to coefficients at $550 \mathrm{~nm}$ wavelength) were applied as in (Glißet al., in preparation), the AeroCom evaluation analysis of the Control 2019 experiment, analysing AeroCom simulations of the year 2010 in detail.

\subsection{Models}

A set of 11 climate models is used in this study. Their main characteristics are reported in Table 2. These models can be separated into three main groups.

\subsubsection{CAMS-Reanalysis}

The CAMS reanalysis, which is the successor to the MACC reanalysis (Monitoring Atmospheric Composition and Climate), is the latest global reanalysis dataset of atmospheric composition produced by the Copernicus Atmosphere Monitoring Service (Inness et al., 2019). It is produced using 4DVar data assimilation in the CY42R1 model cycle of the ECMWF (European Centre for Medium-Range Weather Forecasts) Integrated Forecast System (IFS), with 60 hybrid sigma/pressure vertical levels. The model used in the CAMS reanalysis includes several updates to the aerosol and chemistry modules on top of the standard CY42R1 release. The IFS model assimilates several satellite products, from aerosols (AOD) to greenhouse gases (CO2, CH4) Inness et al. (2019), where most relevant for aerosol trends are data from both MODIS sensors and AATSR/ATSR2. Daily data, from the ECMWF data archive (MARS), were used in this study. The CAMS reanalysis data set covers the period January 2003 to near real time. The three first years of this study period (2000-2002) are missing for this model.

\subsubsection{AeroCom phase III}

The AeroCom-project is an open international initiative of scientists interested in the advancement of the understanding of the global aerosol and its impact on climate (Schulz et al., 2006). Different model experiments have been conducted during the 
third phase of this project, initiated in 2015, in order to investigate specific topics (eg dust, volcanic aerosols, aerosol absorption, hygroscopicity, etc). The model versions are also as close as possible linked to those GCM versions used for CMIP6 and for instance AerChemMIP climate experiments.

In this study, we use the model outputs from the historical AeroCom experiment, whose main aim is to understand the regional trends in aerosol distribution from 1850 to 2015 and to quantify the aerosol forcing with a main emphasis on the direct aerosol effect. The models were run in various configurations, providing different degrees of constraints on the evolving meteorological conditions, such as using monthly fixed sea-surface temperature (SST), historically evolving SSTs, and basic meteorology fields e.g. wind for a given year.

\subsubsection{CMIP6}

The upcoming 2024 IPCC sixth assessment report (AR6) will feature new state-of-the-art CMIP6 (Couple Model Intercomparison Project, Phase 6) models with model runs in higher resolution and with new physical processes. An overview of the experimental design and organisation can be found in Eyring et al. (2016). In this study, we use a preliminary extract of the data of four CMIP6 models from the historical experiment, as available on ESGF nodes, which provided output from 1850 to 2014. 2014 was selected as the last year of the study period of the analysis presented here.

\section{Methods}

\subsection{Regional time series}

Due to the nature of the processes involved in the emission and the deposition of aerosols, one can expect different trends in different regions of the world. Instead of investigating the trends obtained at each individual observation station in a given region, we resort here to the analysis of average regional time series as computed by assembling all measurements at stations in each region into one average time series. A first advantage of this method is that a single trend can be computed in a given region, with an associated significance and uncertainty, which is not as easy to define when combining the trends for individual sites together. Also, with our aggregation method, even a station that has not provided a sufficient amount of data for computing a trend at its location can still contribute to the computation of a regional time series. The computation of such aggregated regional time series makes most sense in regions exhibiting similar seasonal patterns.

\subsubsection{Regions definition and observations coverage}

160 Seven regions are considered in this study. The definition of these regions has been done in a pragmatic way to limit the number of geographic areas investigated, but altogether also provides a global coverage when considering the ensemble of all regions.The Americas and Africa have been separated in a northern and southern section. In order to assemble the sites most affected by Saharan dust, the North Africa region has been extended in the North beyond the continent itself. Stations located in the south of Spain, Cyprus and Greece contribute to the regional time series in the region we are calling North Africa. 

the highest concentrations of instruments monitoring aerosol trends.

- AERONET is the most important network in terms of number of instruments. More than 1000 observation points, with more or less long time series, are found across the globe. The highest density of instruments is in Europe and in the central part of North America (US). The lowest densities are found in southern Africa and Australia.

- Particulate Matter: 212 instruments are used in this study and are spread mostly over Europe and North America.

- $\mathrm{SO}_{4}$ : Altogether 346 instruments have been operating, mostly in North America and Europe. A few stations are also located in Asia and North Africa.

- $\sigma_{s p}$ and $\sigma_{a p}$ : Combined for both parameters circa 50 stations are spread over North America, Europe, North Africa and Asia. Due to time coverage issues (2005 is the first year where in situ optical data are available in the European time series), the data from 2000 up to the year 2018 were used to compute the regional time series of these two parameters.

\subsubsection{Time series aggregation requirements}

The regional time series are computed by combining, for each month, the valid data of all the stations in the corresponding region. In order to construct consistent and robust regional time series, some additional criteria are required to be met to provide a valid point (a station with valid measurements) going into the regional time series. Stations having operated very shortly (e.g AERONET DRAGON campaign stations) are eliminated by requiring a minimum of 300 valid daily measurements in the whole period from 2000 to 2014, which reduces, as an illustration, the number of AERONET stations from 1010 to 437. A minimum of three valid points (daily or monthly depending on the available resolution) is required per month to be present in the overall regional time series. The list of the station names contributing to the computation of the regional time series can be found in the supplementary info.

When all criteria are fulfilled for a given month in the regional time series, the median, the first and third quartiles are computed from all valid data points available. The quartiles provide an indication of the intra-regional variability. An example of regional time-series is shown in Figure 3 for AOD.

\subsection{Trends calculation}

\subsubsection{Yearly, regional time series}

For all of the parameters, the trends are computed based on the yearly averages of the regional time series. Using the yearly averages eliminates any issues caused by the seasonal cycles (observed for most of the aerosol parameters used in this study) during the calculation of the trend slope. In order to ensure the statistical robustness of these yearly averages, the time averaging is performed step-by-step with specific time constraints. By starting at the finest time resolution available in the data, monthly, seasonal and then yearly averages are computed when the following criteria are fulfilled: 
- at least 5 days per month are available (when daily observations are available).

- at least 1 month per season is present with data (seasons defined as JFM, AMJ, JAS, OND).

- all 4 seasons are available for a given year.

These temporal constraints offer a reasonable compromise between the availability and robustness of the yearly statistics.

\subsubsection{Trends computation}

We use the same methodology as described by Aas et al. (2019) to derive the trends of the regional time series. The significance of the trends is tested with the Mann-Kendall test. The related p-value is used to determine if the trend is significant or not within a confidence interval of $95 \%$. The slope is calculated with the Theil-Sen estimator which is less sensitive to outliers than standard least-squares methods. At least least 7 valid yearly regional averages (50\% of time coverage) are required in the regional time series for the computation of a slope.

An uncertainty is provided for each trend by combining the error of the slope calculation itself to the error of the residuals:

Uncertainty $=\sqrt{\left(\frac{\Delta m}{y(2000)}\right)^{2}+\left(\frac{m \cdot \Delta r}{y(2000)^{2}}\right)^{2}}$

where $\Delta m$ is the Theil-Sen estimator 95\% confidence interval, $y(2000)$ is the value of the regression line at the year 2000, $m$ is the value of the Theil-Sen slope and $\Delta r$ is the averaged error on the residuals.

The trend is provided as a relative trend (\%/yr) with respect to the first year of the time period (2000).

\subsection{Representativity of the trends}

The number of available points used to compute the regional time series is not constant in time. For a given observation station, the number of points available might vary in time due to the nature of the measurements. For instance, classic sun photometers only measure in the daytime and in cloud free conditions. Due to seasonal daylight and cloud condition variations, clear seasonal cycles are observed in the number of observations of AOD. The density of the different observation networks can also change with time. The early development of the different observation networks usually coincided with an increase in the number of observation stations. More recently, primarily for funding reasons, some networks have reduced the number of stations. This variation in the number of available measurements raises the question of time representativity for the computation of the trends.

Associated with this time representativity issue comes the space representativity issue. The data coverage is uneven across the different regions. Moreover, within a single region, the observation stations might be located in contrasting environments. Stations located in environments that are more urban, or rural, or mostly affected by natural particles, might have trends differing from the trend associated with the whole region.

Some studies have focused on the representativity of the observation stations by investigating the biases of different optical properties (Wang et al., 2018; Schutgens et al., 2017; Schutgens, 2019). The analysis here is dedicated to characterise the 
representativity of the observation networks specifically for the purpose of computing the trends. These two perspectives on representativity might give different results, since a station associated with a bias, could still have a representative tendency in time. In order to evaluate the effect of the partial space and time sampling of the observations for the evaluation of the trends, two sensitivity studies, focusing on the time sampling and the space sampling, have been conducted using model subsets of data. For each of these studies, the trends are computed for one reference $(R e f)$ and one experiment (Exp) dataset, and compared with each other.

- Time representativity study

- Ref time: Collocation in space and time

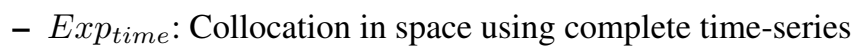

- Space representativity study

- Re $f_{\text {space }}$ : Collocation in space using complete time-series (=Exptime)

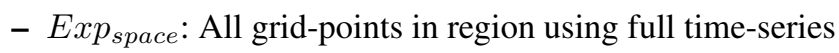

The difference between the relative trends are computed for each parameter and region. Those differences are then converted into a score (\%) by using a normal distribution $f$ described by a mean $\mu=0$ and a standard deviation of $\sigma=0.5$. The choice of these parameters leads to a representativity score of $100 \%$ when there is no difference in the trends of a reference and an experiment dataset, while a difference of $0.5 \% / y r$ would indicate a representativity score of $50 \%$.

For a given parameter $p$ and a region $r$, the representativity $\operatorname{Rep}(p, r)$ is calculated as following

$\operatorname{Rep}_{\text {space }, \text { time }}(p, r)=f\left(\left|\tilde{t}_{\operatorname{Exp}_{\text {space }, \text { time }}(p, r)}-\tilde{t}_{\operatorname{Ref}_{\text {space }, \text { time }}(p, r)}\right|\right)$

where $\tilde{t}$ is the relative trend of the corresponding dataset.

Finally, the total score is computed as the mean of the time and the space representativities.

An example of the calculation is presented in Figure 4 for AOD in Europe and North America. In both regions, the Ref time dataset, corresponding to the available observations, reveals strong seasonal cycles when considering the number of points used to compute the regional time-series. These cycles are observed with most of the sun photometer datasets since the instruments only operate during daytime and cloud free conditions, and the amount of daylight and clouds varies with the season. Together with this seasonal cycle, one observes an increase in the number of points with time, which reflects the increasing number of stations over these two regions.

The trends in Europe show similar values for the time study, which means that the trend is not greatly affected by the variation of the available measurements in time. The difference is larger when considering all the grid-boxes of the domain, but the overall difference of the two studies corresponds to a representativity of 69\%. In North America, the difference in the three trends is larger, outstanding is the space study trend. This means that the trend obtained in the whole region is significantly 

mentioned that the ocean grid-points are not filtered out when computing the trends over the whole domain. For this reason, the regions containing a greater proportion of ocean grid-points, where the trends are most likely to differ from those observed over land, will tend to have a lower spatial representativity, such as North America.

This representativity study illustrates that the partial coverage in time and space of the observations leads, in some cases, to artificial trends. The representativity scores are discussed for each parameter in the following section together with the trend estimate results.

\section{Results}

\subsection{Trends in observations}

This sections presents the trends in the observations computed for the different parameters and over the predefined regions. In order to compare the trends observed for the set of nine aerosol parameters in a consistent manner, we focus on the relative trends, with the reference set to the year 2000, as the first year of the study period. The means for the year 2000, reported in Table 3, reveal a large inter-regional variability.

The AOD is more than three times higher in Asia $(\mathrm{AOD}=0.35)$ than in North America and Australia $(\mathrm{AOD}=0.10)$. Intermediate AOD values are found in Europe and South Africa, while the second highest load is found in North Africa (AOD=0.26). In most regions, the AOD is largely dominated by its fine fraction ( $\mathrm{AOD}<1 \mu \mathrm{m})$, but this is not the case in North Africa (or Australia), where the persistent presence of desert dust makes the coarse mode (AOD $>1 \mu \mathrm{m})$ contribution to the total AOD similar in size to the fine mode contribution. This predominance of coarse particles is reflected in the AE values which exhibit lower values in North Africa (AE=0.72) and Australia (AE=0.97).

The PM observations are primarily available from Europe and North America. $\mathrm{PM}_{10}$ observations are also available in the North Africa region as defined in this analysis, but these stations are located in the northern part of the region, i.e., in southern Europe, which is less affected by the dust sources than the AERONET stations, which cover the whole region including the surrounding deserts. Both $\mathrm{PM}_{10}$ and $\mathrm{PM}_{2.5}$ are larger in Europe than in North America, with different relative proportions. In Europe, $\mathrm{PM}_{2.5}$ represent $75 \%$ of the $\mathrm{PM}_{10}$, as compared to on $57 \%$ in North America.

$\mathrm{SO}_{4}$ means (surface mass concentrations) for the year 2000 ranges between 1.45 and $2.98 \mu \mathrm{g} \cdot \mathrm{m}^{-3}$ with the lowest value occurring in North America and the highest value in North Africa (sites in southern Europe). Similar means are found in Europe and Asia, around $2 \mu \mathrm{g} . \mathrm{m}^{-3}$, though one should bear in mind that there are relatively few sites in Asia and they are not located in the most polluted areas in China and India (Aas et al., 2019).

Analogous to the surface $\mathrm{PM}_{10}$ measurements, $\sigma_{s p}$ is higher in Europe $\left(33 \mu \mathrm{g} . \mathrm{m}^{-3}\right)$ than in North America $\left(25 \mu \mathrm{g} . \mathrm{m}^{-3}\right)$. The same feature is found for $\sigma_{a p}$ which also has higher values in Europe.

The relative trends for the 2000-2014 period are shown in Figure 5. The heatmap is dominated by blue color, which indicates mostly negative trends, especially when considering the extensive parameters. Usually, the lowest p-values $(<0.05)$ are associated with the lowest uncertainties not shown in the same figure though. The largest circles (highest significance of trend) 
are associated with a rather certain decrease/increase of the aerosol property in the time period 2000-2014 since the value of the trend is greater than the uncertainty. The uncertainties are presented in Figure 6.

- In Europe, both columnar and surface parameters reveal statistically significant decreases, with the exception of $\sigma_{a p}$ for which the observed decrease is not significant. For this last parameter, the associated uncertainty of the trend exceeds the trend itself. This large uncertainty is linked to the low data coverage in the earliest years. For the other parameters, the uncertainties are lower than the trends. A decrease in AOD (-2.8\%/yr) is found for both fine and coarse mode particles. This is consistent with the negative trends found at some individual stations in this region (Glantz et al., 2019). The fine mode is decreasing more than the coarse mode, which is consistent with the decrease observed for AE. The same shift in aerosol size is found at the surface since $\mathrm{PM}_{2.5}$ has decreased by a factor of two relative to $\mathrm{PM}_{10}$. These trends could result from the mitigation measures aiming at reduced anthropogenic aerosol emissions. This is more directly observed in the decrease of $\mathrm{SO}_{4}(-1.5 \% / \mathrm{yr})$. We find a somewhat lower trend than what was reported in Aas et al. (2019) $(-2.67 \% / y r)$, but that could be explained by the differences in the methodology (trends computed from the regional time series, in this study, against a statistical average of the trends computed at the individual stations) and/or the definition of the region. The stations in the Mediterranean Basin, where a larger decrease is found ( $-4.3 \% / y r)$, are attributed to the North African region in this study.

The representativity study reveals that the observed trends are actually representative for the whole period and region for all of the parameters, except for $\sigma_{s p}$ and $\sigma_{a p}$ due to the lack of observations in the earliest period. A good agreement is found with the trends obtained at individual stations and reported by Collaud Coen, which reports on decreases of $-2.92 \% / \mathrm{yr}$ for $\sigma_{s p}$ and $-4.2 \% / \mathrm{yr}$ for $\sigma_{a p}$, as compared to $-2.5 \% / \mathrm{yr}$ and $-2.0 \% / \mathrm{yr}$ in this study.

- In North America, similar trends are found for the columnar properties as were found for Europe. AOD is decreasing at a rate of $1.3 \% / y r$, a $55 \%$ percent smaller trend than observed in Europe, but the North America reference value in 2000 is $40 \%$ lower than the reference value in Europe. One can note that the representativity scores are higher for AE than for AOD, while these two parameters have the same amount of data. This means that the trends are probably smoother, in space and time, when comparing AE with AOD, which makes the same amount of available observations more representative in the case of AE.The decreases observed for both $\mathrm{PM}_{2.5}(-2.1 \% / \mathrm{yr})$ and $\mathrm{PM}_{10}-1.6 \% / \mathrm{yr}$ are significant and in the same range of values than the trends found in Europe. However, the actual trends for $\mathrm{PM}_{10}$ and $\mathrm{PM}_{2.5}$ are probably somewhat higher than found here. The possible bias is caused by increased relative humidity during weighing, resulting 315 in more particle bound water and thus higher mass, after the relocation of the laboratory in 2011. Hand et al. (2019) reported that the decrease in $\mathrm{PM}_{2.5}$ from 2005 through 2016 was $-2.6 \% / \mathrm{yr}$, while it was $-3.9 \% / \mathrm{yr}$ for the reconstructed fine mass correcting for the possible bias in the measurements. $\mathrm{SO}_{4}$ decreases by about $3 \% / \mathrm{yr}$, which is twice as large as the decrease observed in Europe, where the reference value is however larger than in North America. The sulfate trend is similar to the trend reported by Aas et al. (2019) in this region (-3.15\%/yr). The regional time series are extend farther back in time for $\sigma_{s p}$ and $\sigma_{a p}$ in North America than in Europe. However, no significant trends are found for these data sets. Collaud Coen finds a large decrease for $\sigma_{s p}(-2.57 \% / \mathrm{yr})$ which is not found in this study, when using regional 
averaged time series to calculate the trend rather than regionally averaged trends as was done by Collaud Coen. Similar values are found in this study and by Collaud Coen for $\sigma_{a p}(-1.85 \% / \mathrm{yr})$ despite the fact the trend is not significant. The IMPROVE network also measures filter absorption using a Hybrid Integrating Plate and Sphere (HIPS) system (White et al., 2016). These data are not included in this study, but White et al. (2016) reports a significant decrease (-2.7\%/y) in the light absorption coefficients from 2005 to 2015.

- All of the columnar properties show decreasing trends in South America. All of the trends are significant, except for $\mathrm{AOD}>1 \mu \mathrm{m}$. As shown in the regional time series in Figure 3, the observed decrease in AOD coincides with a global diminution of the intensity of the seasonal peaks happening around September and resulting from the Amazonian forest fires (Aragão et al., 2018). These peaks are highly variable from year to year and could greatly affect the trend when considering another time period. With a rate of $-2.0 \% / \mathrm{yr}$, the largest decrease of $\mathrm{AE}$ is found in this region. While no significant trend is found for $\mathrm{AOD}>1 \mu \mathrm{m}$, the tendency towards increasing coarse particles is probably due to the production of local dust as a result of the increasing deforestation (Werth and Avissar, 2002; Betts et al., 2008).

- In North Africa, while significant decreases are found for all AOD parameters, an increase of AE (+1.1\%/yr) is observed, which indicates an increase in the proportion of fine particles with time. This is consistent when considering the AOD of the fine and coarse modes, which reveal a larger decrease for AOD $>1 \mu \mathrm{m}$. Chin et al. (2014) also found a decrease in dust in the Sahara/Sahel in the time period 1980-2009 due to reduced 10m-wind speed, possibly caused by an increase in sea surface temperature (SST) in the North Atlantic.

- $\mathrm{AE}$ is also increasing in Asia as a combination of a (not significant) increase in $\mathrm{AOD}<1 \mu \mathrm{m}$ and a significant increase in $\mathrm{AOD}>1 \mu \mathrm{m}$. The increase in $\mathrm{AE}$ is likely tied to increases in anthropogenic emissions which are associated with fine mode aerosol. This result is consistent with the trend reported by Yoon et al. (2012) at some individual stations. At the same time, we observe an increase of $\mathrm{SO}_{4}$ of 3.8\%/yr, which is consistent with the trend reported in Aas et al. (2019). This increase is associated with a large uncertainty $( \pm 4 \% / y r)$ due to a drop in the already small number of stations available in the region, especially between 2010 and 2012. Indeed, with a maximum of 12 stations, a few stations missing can greatly affect the computation of the regional time series. This is reflected by the representativity study which reveals a score lower than $40 \%$ for this parameter.

- No significant trends could be found in Australia, although the representativity is greater than $50 \%$ for AOD, AOD $<1 \mu \mathrm{m}$ and $\mathrm{AE}$.

This multi-parameter trend analysis reveals a decrease in most of the parameters relating to aerosol burden (extensive parameters), both in the total column and at the surface level. In Asia, the trends in $\mathrm{AOD}<1 \mu \mathrm{m}, \mathrm{AE}$ and $\mathrm{SO}_{4}$ suggest an increase in the proportion of the finer particles. While differences might be expected when comparing regional trends with trends computed at individual stations, the trends are usually consistent with those previously reported in the literature. de Meij et al. (2012) focused on regional AOD trends in the 2000-2009 period; despite the differences in the study periods and the methodologies involved, consistent trends can be found in most of the regions with the trends obtained in this study. 


\subsection{Evaluation of the models trends against observations}

In order to evaluate the trends from the models, the regional time series have been computed with the model output collocated in space and time to the available observations at the station level. The model trends are computed in a similar manner to the trends for the observation datasets. However, for the few models providing output every 5 years (in addition to 2014), the minimum required number of points has been reduced from 7 to 4, so the trends can be computed using the years 2000, 2005, 2010 and 2014. The results, shown in Figure 6, reveal different performances of the various models, for the reproduction of the observed trends, depending on the parameters and the regions.

- AOD: the models show trends in the same direction as the observations over all the regions except in Asia, where the associated uncertainties are, however, usually larger than the trend values. Some differences among the three model groups are observed when investigating the different regions:

- EUROPE: all the groups underestimate the observed decrease in AOD. With an average decrease of $-1.0 \% / \mathrm{yr}$, the CMIP6 models exhibit the largest underestimation, while the best performance is obtained with CAMS-Rean $(-2.1 \% / \mathrm{yr})$. The AP3 models trends range from $-1.3 \% / \mathrm{yr}$ to $-2.0 \% / \mathrm{yr}$.

- NAMERICA: in contrast to the results for EUROPE, on average, all of the models overestimate the observed AOD decrease in NAMERICA even though two models of the AP3 group simulate lower trends than are found for observations. The consistency in the trends is very high within the CMIP6 group over this region.

- SAMERICA: CAMS Rean slightly overestimates the observed AOD decrease while all the models of the two other groups underestimate this decrease. A few of the models simulate positive trends, but these are associated with large uncertainties.

- NAFRICA: all the models capture the observed decreasing AOD tendency. With a trend of -3.0\%/yr, CAMS-Rean is the closest to the observed trend $(-2.7 \% / \mathrm{yr})$. AP3 and CMIP6 multi-model trend averages are $-2.0 \% / \mathrm{yr}$ and $-2.2 \% / y r$, respectively.

- ASIA: A large inter-model variability is found in this region where the uncertainty is also significant. The means of the trends of each group range from $-0.2 \% / \mathrm{yr}$ to $+0.2 \% / \mathrm{yr}$.

- AOD $<1 \mu \mathrm{m}$ : usually, the same patterns are found as for AOD. The models that underestimated the AOD underestimate $\mathrm{AOD}<1 \mu \mathrm{m}$ and vice versa. For $\mathrm{AOD}<1 \mu \mathrm{m}$ and the following parameters, only NorESM2 provides data for the CMIP6 group.

- in EUROPE: the underestimation of the decrease captured by the models is larger than the underestimation of AOD.

- ASIA: an increase, associated with large uncertainties is found in both models of the AP3 group (+1.3\%/yr) and observations $(+0.8 \% / \mathrm{yr})$. 
- AOD $>1 \mu \mathrm{m}$ : the performance of the models is not as good as for AOD $<1 \mu \mathrm{m}$. This is also observed when evaluating the models for a single year (Glißet al., in preparation). The inter model variability is also higher since some models simulate $\mathrm{AOD}>1 \mu \mathrm{m}$ trends in opposite directions in some regions.

- EUROPE: while the observations exhibit a significant decrease, CAMS-Rean and all of the AP3 models exhibit increasing values for AOD $>1 \mu \mathrm{m}$. NorESM2 from CMIP6 simulate a decrease consistent with the observations.

- SAMERICA: All of the models simulate large increases, from $+4.3 \% / \mathrm{yr}$ up to $+14.6 \% / \mathrm{yr}$ which are not visible in the observations $(-0.1 \% / \mathrm{yr})$.

- NAFRICA: the models reproduce the observed decrease of 3.3\%/yr to some extent (from $-0.7 \% / \mathrm{yr}$ to $-2.5 \% / \mathrm{yr}$ ). The fact that some models with fixed SST (e.g ECHAM-HAM) reproduce this decrease does not support the hypothesis of the SST changes. The decrease in dust could be caused by increased wet scavenging of dust after coating with anthropogenic sulfate aerosols. The production of high levels of readily soluble materials on the dust surface makes dust aerosols effective cloud condensation nuclei (Fan et al., 2004; Bauer and Koch, 2005; Bauer et al., 2007; Neubauer et al., 2019).

- ASIA: CAMS-Rean captures the same trend as computed with the observations dataset. Like for $\mathrm{AOD}<1 \mu \mathrm{m}$, no certain trend can be identified in this region with the CMIP6 model.

- AE: the trends are usually smaller than for AOD in the respective regions, meaning that the amount of the particles is more subject to variations than the size (type) of these particles. This feature is visible with both observations and models.

- EUROPE and NAMERICA: one model of the AP3 group (ECHAM-HAM) simulates a significant positive trend in $\mathrm{AE}$ while negative tendencies are found in the observation and with the other models.

- SAMERICA: all of the models simulate negative AE trends, most of them significant, in agreement with the observations. CAMS-Rean and the AP3 models tend to underestimate the decrease, while the CMIP6 model tends to overestimate it.

- NAFRICA: CAMS-Rean does an excellent job of reproducing the observed AE increase $(+1.3 \% / \mathrm{yr}$ versus $+1.1 \% / \mathrm{yr})$. The significant trends of the AP3 models range from $-0.5 \% / \mathrm{yr}$ to $+2.0 \% / \mathrm{yr}$. The increase of AE supports the theory of enhanced scavenging of dust by anthropogenic aerosols.

- ASIA: the AP3 models and the CMIP6 model exhibit significant positive trends, which is also the case for the observations. CAMS-Rean does not capture any significant trend in this region.

- $\mathrm{PM}_{2.5}$ : Almost all the models simulate significant decreases over Europe and North America, in good agreement with the observations. The CMIP6 model performs however better in North America, while it underestimates the extent of the decrease in Europe. Further analysis reveals that, despite the fact that it does a good job reproducing the $\mathrm{PM}_{2.5}$ trend in North America, CAMS-Rean exhibits a large positive bias in North America (+100\%). 
- $\mathrm{PM}_{10}$ : In North Africa, only CAMS-Rean reproduces the observed significant decrease. Positive trends are found for all the models of the AP3 and CMIP6 groups. As for $\mathrm{PM}_{2.5}$, NorESM has better performance in North America. CAMSRean produces a trend twice as high as the observed trends both over Europe and North America.

- $\mathrm{SO}_{4}$ : The AP3 and CMIP6 models perform quite well for the $\mathrm{SO}_{4}$ surface concentration. The magnitude of the model trends is however higher than the observed trends in all the regions except North Africa.

- $\sigma_{s p}$ and $\sigma_{a p}$ : as mentioned in the previous section, the observations trends have been computed for these two parameters using data until 2018. The two models providing output for these parameters are NorESM2 and SPRINTARS. NorESM2 provides data until 2014, so the NorESM2 trends correspond to the period [2000-2014], while SPRINTARS provides data until 2018 and thus covers the whole observation period [2000-2018].

- EUROPE: a significant decrease is found in the observations for both $\sigma_{s p}$ and $\sigma_{a p}$ but this is not captured by the models where positive trends are found, although associated with large uncertainties.

- NAMERICA: A significant decrease is found with NorESM2 for $\sigma_{s p}$ which is not seen in the observations. For $\sigma_{a p}$, NorESM2 captures a similar trend as derived from the observations, while SPRINTARS does not. capturing the trends of this parameter. Second, a large inter-model variability is generally found over Asia, where the observed trends are also the most uncertain. Considering the total column, the models usually perform rather well for AOD, AOD $<1 \mu \mathrm{m}$, and $\mathrm{AE}$, but show lower skill for $\mathrm{AOD}>1 \mu \mathrm{m}$. At ground level, the models perform well for both $\mathrm{SO}_{4}$ concentration and PM. The trends in $\sigma_{s p}$ and $\sigma_{a p}$ computed from regional time series are associated with large uncertainties due to the limited number of stations. This is exacerbated by the fact that data was only available from two models for these parameters.

\subsection{Trends in models}

\subsubsection{Global trends}

As discussed previously, the regional trends found are probably not always representative of the trends in the extended regions and over the whole study period. The reasons are the partial spatial and temporal coverage of the ground based observations. Moreover, the observation stations are obviously located on land. This does not allow for a depiction of a global aerosol trends and is unfortunate as sea salt particles are among the most predominant aerosols on Earth (Schulz et al., 2004).

In order to provide an assessment of the aerosol trends at a global scale, we present, in this section, the trends computed with the NorESM2 data (CMIP6 group) using all grid boxes. The calculation of the global trend is made by averaging the absolute trends computed at each grid-point of the model. In order to provide a relative trend, this absolute trend is normalized to the global average of the considered parameter for the year 2000. The global trends are reported for the nine aerosol parameters in Table 4. The global maps, shown in Figure 7, enable investigation of the spatial variability of these trends.

While the observed trends of the three AOD parameters show a decrease in most of the regions of the world, the global AOD trend is actually positive $(+0.2 \% / \mathrm{yr})$. This global increase is also found with other models. Averages of the models from 
the CAMS-Rean and the AP3 groups simulate global trends of about $+0.2 \% / \mathrm{yr}$ and $+0.3 \% / \mathrm{yr}$ respectively. Within the CMIP6 group, IPSL and CESM2 also exhibit positive trends $(+0.7 \% / \mathrm{yr}$ and $+0.3 \% / \mathrm{yr})$, consistent with NorESM2, while CanESM simulates a negative trend $(-0.8 \% / \mathrm{yr})$. The relative increase of $0.2 \% / \mathrm{yr}$ found with NorESM2 corresponds to an absolute rate of +0.0028 /decade, which is in excellent agreement with the global trend (over the oceans) of $+0.003 /$ decade reported by Zhang and Reid (2010) using MODIS data. The increase of AOD is observed to be larger for the fine fraction, with an increase of about $+0.6 \% / \mathrm{yr}$, as compared to $+0.1 \% / \mathrm{yr}$ for AOD $>1 \mu \mathrm{m}$. As seen in Figure 7, similar geographical patterns are found for the three AODs: increase in South-Africa and East-Asia and decrease in Europe and in the US. The increasing AOD observed in Canada is dominated by an increase of $\mathrm{AOD}<1 \mu \mathrm{m}$ in this region. The important increase of AOD in Indonesia seems to be linked to a large increase of AOD $>1 \mu \mathrm{m}$. Over the Pacific Ocean, one region has significant positive modelled trends in both $\mathrm{AOD}$ and $\mathrm{AOD}<1 \mu \mathrm{m}$. Almost no significant trend is found south of $60^{\circ} \mathrm{S}$.

The model also simulates an increase for AE on a global scale, with a rate of $+0.3 \% / y r$. This suggests a shift towards smaller particles. The largest increases are found over Canada, Greenland, Siberia and the Pacific Ocean. There are some distinct outliers around $60^{\circ} \mathrm{S}$. In the Atlantic, we find a decrease of $\mathrm{AE}$, which is consistent with the decrease of $\mathrm{AOD}<1 \mu \mathrm{m}$ in the same region.

The trends in both $\mathrm{PM}_{2.5}$ and $\mathrm{PM}_{10}$ exhibit similar geographical features as are observed for AOD. In addition, one finds large and significantly increasing trends in the high Arctic. The global averages show that $\mathrm{PM}_{2.5}$ is increasing faster than $\mathrm{PM}_{10}$ $(+0.2 \% / \mathrm{yr}$ vs. $+0.1 \% / \mathrm{yr})$, which is consistent with the increasing AE, suggesting a relatively higher fraction of fine particles with time.

The surface $\mathrm{SO}_{4}$ concentration trends map reveals two large contrasting regions. Significant decreases are found over North America and Europe, while significant increases are found over southern and eastern Asia and southern to central parts of Africa. This illustrates the shift of polluting activities from the developed countries to the developing countries during the last two decades. With an overall increase of $+0.4 \% / \mathrm{yr}$, the global trend is positive.

The $\sigma_{s p}$ trends are very similar to those observed for both $\mathrm{PM}_{2.5}$ and $\mathrm{PM}_{10}$. The same geographical patterns are found, as well as the global average trend which amounts to an increase of $0.2 \% / y r$ over the study period.

$\sigma_{a p}$ reveals increasing tendencies over most of the grid-boxes of the model, except in Europe, the eastern part of US, and Australia. This explains why the large positive global trend is obtained for this parameter, with an average of $+1.5 \% / y r$. Further analysis shows a good spatial correlation with the BC OD (Optical Depth) that exhibits a strong global positive trend of $+2.3 \% / y$.

Table 4 also contains the trends computed for the different aerosol parameters when combining only the grid-points where an observation station is located, whether measurements are available or not. Significant differences in 'global' trends can be found when observations are not provided over some regions. This is most obvious for $\mathrm{SO}_{4}$ for which the observation stations are located mostly in Europe and North America and exhibit decreasing values, while only a few stations are located in the regions associated with increasing values. In this case, the computation of the trends by considering only observation station grid-boxes leads to a global decrease of $-1.1 \% / \mathrm{yr}$ while consideration of all of the grid-boxes of the model leads to a global increase of $+0.4 \% / \mathrm{yr}$. 


\subsubsection{Contribution of main aerosol species to the AOD trends}

The averaged global trend computed by NorESM2 indicates an increase of AOD in the 2000-2014 period with a rate of about $0.2 \% / \mathrm{yr}$. The trends in $\mathrm{AE}, \mathrm{AOD}<1 \mu \mathrm{m}$ and $\mathrm{AOD}>1 \mu \mathrm{m}$ indicate that the fine particles are primarily responsible for this increase in the atmospheric column.

In this section, we investigate the trends of the major aerosol species simulated by NorESM2. For that purpose, the absolute trends of the individual contribution of these species to the AOD were computed, as well as the trends in the loads and the emissions. The trends of OD and loads are shown in Figure 8. In this version, NorESM2 simulates a large proportion of sea salt. This is the result of a model tuning used for reaching climate equilibrium. While the model attributes too much OD to SS, the trends should not be affected by this tuning.

The relative increase of AOD of $+0.2 \% / \mathrm{yr}$ corresponds to an absolute increase of $+3.1 \mathrm{e}^{-4} / \mathrm{yr}$. This positive trend is dominated by an increase of the organic aerosols $(\mathrm{OA}), \mathrm{SO}_{4}$ and black carbon, which are responsible for an increase of the OD of about $+2.0 \mathrm{e}^{-4} / \mathrm{yr},+0.7 \mathrm{e}^{-4} / \mathrm{yr}$ and $+0.4 \mathrm{e}^{-4} / \mathrm{yr}$, respectively. The relative OD trends give a different ranking since the highest increase is found for $\mathrm{BC}(+2.5 \% / \mathrm{yr})$, followed by $\mathrm{OA}(+0.5 \% / \mathrm{yr})$. On average, the trends for dust and sea salt are slightly negative $\left(-0.1^{-4} / \mathrm{yr}\right)$.

The trends in OD do not necessarily represent the trends in the aerosol loads, since the different species have different mass extinction coefficients (from this study, dust: $1.8 \mathrm{~m}^{2} \cdot \mathrm{g}^{-1}$, SS: $4.3 \mathrm{~m}^{2} \cdot \mathrm{g}^{-1}$, OA: $5.6 \mathrm{~m}^{2} \cdot \mathrm{g}^{-1}, \mathrm{SO}_{4}: 5.3 \mathrm{~m}^{2} \cdot \mathrm{g}^{-1}$, BC: 7.6 $\mathrm{m}^{2} \cdot \mathrm{g}^{-1}$ ). For sea salt, opposite trends are even observed for the sea salt OD (positive trend) and the sea salt load (negative trend). The analysis of the global maps (not shown in this study) reveals that the largest increases of the sea salt load happen in Indonesia and near the North Pole and result in a relatively larger increase of OD in these areas. This effect relates to the higher relative humidity at these latitudes which makes the sea salt, which is very hygroscopic, more efficient at light extinction.

\section{Conclusions}

The main findings of this multi parameter trends analysis can be listed as follows:

- The observations exhibit mostly negative trends regarding the extensive parameters in the different regions of the world. In Asia, $\mathrm{AE}$ is increasing in time consistent with increases in $\mathrm{AOD}<1 \mu \mathrm{m}$ and $\mathrm{SO}_{4}$, which reflects the regional increase of the anthropogenic aerosols in that region in the overall study period from 2000 to 2014.

- Some observation networks allow for the derivation of representative trends over the whole study period. In other cases, the partial temporal and spatial coverage of the observations can induce artificial and/or highly uncertain trends when using regional time series. $60 \%$ of the 37 trend values computed in this study are significant at the $90 \%$ level.

- The models tend to capture observed AOD, $\mathrm{AE}, \mathrm{SO}_{4}$ and $\mathrm{PM}$ trends but show larger discrepancies regarding $\mathrm{AOD}>1 \mu \mathrm{m}$. The smaller amount of data available for establishing $\sigma_{s p}$ and $\sigma_{a p}$ trends makes the validation of the modeled trends more uncertain. 
- The global trends computed using model data give a different picture than the trends obtained when using only groundbased observations. The rather good agreement of the trends, across different aerosol parameters between models and observations, when co-locating them in time and space, implies that global model trends, including those in poorly monitored regions, are likely correct.

- The global trends computed with the model data show mostly positive trends for all the parameters related to aerosol loading. The trends in AOD are dominated by the increase of the fine particles both in the column and at the surface. This tendency toward finer particles is consistent with the positive trend in AE. This increase appears to be dominated by the organic aerosols, for which the emissions have increased in the study period, and by the $\mathrm{SO}_{4}$ whose emissions were shifted from Europe and North America to Africa and East Asia where a global positive $\mathrm{SO}_{4}$ trend is found.

Some elements were not considered in this study which could be investigated in order to complete the aerosol trends picture:

- Some regions are associated with strong seasonal cycles. In South America, the regional time series shows high peaks in AOD, associated with forest fires in the late summer, whose intensity greatly varies from year to year. In Africa, a strong seasonal contrast is also found due to the transport of desert dust at altitude in the summer months (Mortier et al., 2016; Ogunjobi et al., 2008). The computation of the seasonal trends would allow characterization of the tendencies in such extreme or synoptic aerosol events.

- This study shows that the trends computed from the ground-based observations networks are not representative of the global aerosol trends due to the inhomogeneities in data spatial coverage. The satellites providing a global Earth observation could be utilized for the evaluation of the model trends in the regions lacking observations and over the oceans (Hsu et al., 2012; Zhang and Reid, 2010).

- The trends in the meteorological parameters could be investigated in parallel with the aerosol trends because they affect the aerosols life cycle and their optical properties (Che et al., 2019). Hypothetical trends in wind velocity could produce trends in the loads of sea salt and dust and, as seen in the last section, trends in OD could also be enhanced by relative humidity changes. Changes in temperature could impact the magnitude of the biogenic emissions. Indeed, increasing temperatures, associated with changes in land use and high atmospheric $\mathrm{CO} 2$ concentrations have been shown to lead to an increase of the BVOC emissions (Peñuelas and Staudt, 2010). Finally, trends in precipitation that are responsible for aerosol wet scavenging would directly produce trends in aerosol loads.

- Several studies have linked the trends in anthropogenic aerosols to radiative forcing variations while investigating sources of global dimming and brightening Streets et al. (2006); Norris and Wild (2007). It could be of interest to evaluate how much the modeled trends deviations, as compared to the observations, are affecting the calculation of the radiative forcing, in the different regions of the world, and at a global scale.

- While the mountain sites were excluded from this study, it could be of interest to investigate the trends at higher altitude (which may be related to changes in long range transport) by including the in situ and remote sensing stations higher than 1000 m (Jungfraujoch, Mauna Loa Observatory, ...). 
- While assembling the dataset for this analysis, it appeared that more observations ( $\sigma_{a p}$ in the US) could be utilized. Due to time limitations, these data could not be integrated in the study, but could be considered in the future to enrich both databases. In addition, more models and diagnostics from the AeroCom and CMIP6 ensemble should be added into the analysis when data become available to eventually confirm the regional and global trends for all parameters.

Code availability. The observation and model data were read and collocated with the pyaerocom python library (https://github.com/metno/ pyaerocom, version 0.8 .0 ).

Author contributions. A. M. has coordinated the study, has been responsible for the statistical calculation and analysis and wrote the paper,

555 J. G. is the main developer of the pyaerocom library, M. S. has provided feedback on the methods and the manuscript, W. A, E. A, J. H, and P. L have provided in situ data, contributed to the observation dataset section writing and provided feedback on the manuscript, B. H. is the PI of AERONET, H. B., M. C., P. G., Z. H., Z. K., A. K., T. L., G. M., D. N., D. O., K. S., T. T., and S. T. have provided model output data and feedback on the manuscript.

Competing interests. The authors declare no competing interests.

Acknowledgements. Data providers from all the regional and global networks are greatly acknowledged for sharing and submitting their data to be used. DN acknowledges funding from the European Union's Horizon 2020 research and innovation programme project FORCeS under grant agreement No 821205. The ECHAM-HAMMOZ model is developed by a consortium composed of ETH Zurich, Max Planck Institut für Meteorologie, Forschungszentrum Jülich, University of Oxford, the Finnish Meteorological Institute and the Leibniz Institute for Tropospheric Research, and managed by the Center for Climate Systems Modeling (C2SM) at ETH Zurich.

565 The CESM project is supported primarily by the National Science Foundation (NSF). This material is based upon work supported by the National Center for Atmospheric Research, which is a major facility sponsored by the NSF under Cooperative Agreement No. 1852977. Computing and data storage resources, including the Cheyenne supercomputer (doi:10.5065/D6RX99HX), were provided by the Computational and Information Systems Laboratory (CISL) at NCAR. All simulations were carried out on the Cheyenne high-performance computing platform https://www2.cisl.ucar.edu/user-support/acknowledging-ncarcisl, and are available to the community via the Earth System Grid. 


\section{References}

Aas, W., Mortier, A., Bowersox, V., Cherian, R., Faluvegi, G., Fagerli, H., Hand, J., Klimont, Z., Galy-Lacaux, C., Lehmann, C. M., et al.: Global and regional trends of atmospheric sulfur, Scientific reports, 9, 953, 2019.

Aragão, L. E., Anderson, L. O., Fonseca, M. G., Rosan, T. M., Vedovato, L. B., Wagner, F. H., Silva, C. V., Junior, C. H. S., Arai, E., Aguiar, A. P., et al.: 21st Century drought-related fires counteract the decline of Amazon deforestation carbon emissions, Nature communications, $9,536,2018$.

Barreto, Á., Cuevas Agulló, E., Granados-Muñoz, M. J., Alados-Arboledas, L., Romero Campos, P. M., Gröbner, J., Kouremeti, N., Almansa Rodríguez, A. F., Stone, T., Toledano, C., et al.: The new sun-sky-lunar Cimel CE318-T multiband photometer-a comprehensive performance evaluation, 2016.

Bauer, S. and Koch, D.: Impact of heterogeneous sulfate formation at mineral dust surfaces on aerosol loads and radiative forcing in the Goddard Institute for Space Studies general circulation model, Journal of Geophysical Research: Atmospheres, 110, 2005.

Bauer, S., Mishchenko, M., Lacis, A., Zhang, S., Perlwitz, J., and Metzger, S.: Do sulfate and nitrate coatings on mineral dust have important effects on radiative properties and climate modeling?, Journal of Geophysical Research: Atmospheres, 112, 2007.

Bell, M. L., Davis, D. L., and Fletcher, T.: A retrospective assessment of mortality from the London smog episode of 1952: the role of influenza and pollution., Environmental health perspectives, 112, 6-8, 2004.

Betts, R., Sanderson, M., and Woodward, S.: Effects of large-scale Amazon forest degradation on climate and air quality through fluxes of carbon dioxide, water, energy, mineral dust and isoprene, Philosophical Transactions of the Royal Society B: Biological Sciences, 363 , 1873-1880, 2008.

Bian, H., Chin, M., Hauglustaine, D. A., Schulz, M., Myhre, G., Bauer, S. E., Lund, M. T., Karydis, V. A., Kucsera, T. L., Pan, X., et al.: Investigation of global particulate nitrate from the AeroCom phase III experiment, Atmospheric Chemistry and Physics, 17, $12911,2017$.

Bryner, G. C.: Blue skies, green politics: The clean air act of 1990, 1995.

Burnett, R. T., Pope III, C. A., Ezzati, M., Olives, C., Lim, S. S., Mehta, S., Shin, H. H., Singh, G., Hubbell, B., Brauer, M., et al.: An integrated risk function for estimating the global burden of disease attributable to ambient fine particulate matter exposure, Environmental health perspectives, 122, 397-403, 2014.

Che, H., Gui, K., Xia, X., Wang, Y., Holben, B. N., Goloub, P., Cuevas-Agulló, E., Wang, H., Zheng, Y., Zhao, H., et al.: Large contribution of meteorological factors to inter-decadal changes in regional aerosol optical depth, Atmospheric Chemistry and Physics, 19, 10 497-10 523, 2019.

Chin, M., Ginoux, P., Kinne, S., Torres, O., Holben, B. N., Duncan, B. N., Martin, R. V., Logan, J. A., Higurashi, A., and Nakajima, T.: Tropospheric aerosol optical thickness from the GOCART model and comparisons with satellite and Sun photometer measurements, Journal of the atmospheric sciences, 59, 461-483, 2002.

Chin, M., Diehl, T., Tan, Q., Prospero, J., Kahn, R., Remer, L., Yu, H., Sayer, A., Bian, H., Geogdzhayev, I., et al.: Multi-decadal aerosol variations from 1980 to 2009: a perspective from observations and a global model, 2014.

Colarco, P., da Silva, A., Chin, M., and Diehl, T.: Online simulations of global aerosol distributions in the NASA GEOS-4 model and comparisons to satellite and ground-based aerosol optical depth, Journal of Geophysical Research: Atmospheres, $115,2010$.

Collaud Coen, .: Multidecadal trend analysis of aerosol radiative properties at a global scale, in preparation.

Danabasoglu, G., Lamarque, J.-F., B. J., Bailey, D. A., DuVivier, A. K., and et al.: The Community Earth System Model version 2 (CESM2), Journal of Advances in Modeling Earth Systems, submitted. 
de Meij, A., Pozzer, A., and Lelieveld, J.: Trend analysis in aerosol optical depths and pollutant emission estimates between 2000 and 2009, Atmospheric Environment, 51, 75 - 85, https://doi.org/https://doi.org/10.1016/j.atmosenv.2012.01.059, http://www.sciencedirect. com/science/article/pii/S1352231012000805, 2012.

Eyring, V., Bony, S., Meehl, G. A., Senior, C. A., Stevens, B., Stouffer, R. J., and Taylor, K. E.: Overview of the Coupled Model Intercomparison Project Phase 6 (CMIP6) experimental design and organization, Geoscientific Model Development (Online), 9, 2016.

Fan, S.-M., Horowitz, L. W., Levy, H., and Moxim, W. J.: Impact of air pollution on wet deposition of mineral dust aerosols, Geophysical research letters, 31, 2004.

Giles, D. M., Sinyuk, A., Sorokin, M. G., Schafer, J. S., Smirnov, A., Slutsker, I., Eck, T. F., Holben, B. N., Lewis, J. R., Campbell, J. R., et al.: Advancements in the Aerosol Robotic Network (AERONET) Version 3 database-automated near-real-time quality control algorithm with improved cloud screening for Sun photometer aerosol optical depth (AOD) measurements, Atmospheric Measurement Techniques, 12, 169-209, 2019.

Glantz, P., Freud, E., Johansson, C., Noone, K. J., and Tesche, M.: Trends in MODIS and AERONET derived aerosol optical thickness over Northern Europe, Tellus B: Chemical and Physical Meteorology, 71, 1-20, https://doi.org/10.1080/16000889.2018.1554414, https: //doi.org/10.1080/16000889.2018.1554414, 2019.

Gliß, J. et al.: Multi-model evaluation of modelled aerosol optical properties in the AeroCom Phase III Control experiment using ground and space based columnar observations from AERONET, MODIS, and AATSR and surface in-situ observations from GAW sites, Atmospheric Chemistry in Physics, in preparation.

Hand, J., Prenni, A., Schichtel, B., Malm, W., and Chow, J.: Trends in remote PM2.5 residual mass across the United States: Implications for aerosol mass reconstruction in the IMPROVE network, Atmospheric Environment, 203 , 141 - 152, https://doi.org/https://doi.org/10.1016/j.atmosenv.2019.01.049, 2019.

Haywood, J. and Boucher, O.: Estimates of the direct and indirect radiative forcing due to tropospheric aerosols: A review, Reviews of geophysics, 38, 513-543, 2000.

Holben, B. N., Tanre, D., Smirnov, A., Eck, T., Slutsker, I., Abuhassan, N., Newcomb, W., Schafer, J., Chatenet, B., Lavenu, F., et al.: An emerging ground-based aerosol climatology: Aerosol optical depth from AERONET, Journal of Geophysical Research: Atmospheres, 106, 12 067-12 097, 2001.

Hsu, N., Gautam, R., Sayer, A., Bettenhausen, C., Li, C., Jeong, M., Tsay, S., and Holben, B.: Global and regional trends of aerosol optical depth over land and ocean using SeaWiFS measurements from 1997 to 2010, 2012.

Inness, A., Ades, M., Agusti-Panareda, A., Barré, J., Benedictow, A., Blechschmidt, A.-M., Dominguez, J. J., Engelen, R., Eskes, H., Flemming, J., et al.: The CAMS reanalysis of atmospheric composition, Atmospheric Chemistry and Physics, 19, 3515-3556, 2019.

Johnson, B., Shine, K., and Forster, P.: The semi-direct aerosol effect: Impact of absorbing aerosols on marine stratocumulus, Quarterly Journal of the Royal Meteorological Society, 130, 1407-1422, 2004.

Kaufman, Y. J., Tanré, D., and Boucher, O.: A satellite view of aerosols in the climate system, Nature, 419, $215,2002$.

Kinne, S., O’Donnel, D., Stier, P., Kloster, S., Zhang, K., Schmidt, H., Rast, S., Giorgetta, M., Eck, T. F., and Stevens, B.: MAC-v1: A new global aerosol climatology for climate studies, Journal of Advances in Modeling Earth Systems, 5, 704-740, 2013.

Kirkevåg, A., Grini, A., Olivié, D., Seland, O., Alterskjær, K., Hummel, M., Karset, I. H., Lewinschal, A., Liu, X., Makkonen, R., et al.: A production-tagged aerosol module for Earth system models, OsloAero5. 3-extensions and updates for CAM5. 3-Oslo, Geoscientific Model Development, 2018. 
Labordena, M., Neubauer, D., Folini, D., Patt, A., and Lilliestam, J.: Blue skies over China: The effect of pollution-control on solar power generation and revenues, PloS one, 13, e0207 028, 2018.

Li, X., Wagner, F., Peng, W., Yang, J., and Mauzerall, D. L.: Reduction of solar photovoltaic resources due to air pollution in China, Proceedings of the National Academy of Sciences, 114, 11 867-11 872, https://doi.org/10.1073/pnas.1711462114, https://www.pnas.org/ content/114/45/11867, 2017.

Likens, G. E., Butler, T. J., and Buso, D. C.: Long-and short-term changes in sulfate deposition: effects of the 1990 Clean Air Act Amendments, Biogeochemistry, 52, 1-11, 2001.

Lohmann, U. and Feichter, J.: Global indirect aerosol effects: a review, Atmospheric Chemistry and Physics, 5, 715-737, 2005.

Lund, M. T., Myhre, G., Haslerud, A. S., Skeie, R. B., Griesfeller, J., Platt, S. M., Kumar, R., Myhre, C. L., and Schulz, M.: Concentrations and radiative forcing of anthropogenic aerosols from 1750 to 2014 simulated with the Oslo CTM3 and CEDS emission inventory, 2018.

Lurton, T. et al.: Implementation of the CMIP6 forcing data in the IPSL-CM6A-LR model, Journal of Advances in Modeling Earth Systems, 2019.

Mortier, A., Goloub, P., Derimian, Y., Tanré, D., Podvin, T., Blarel, L., Deroo, C., Marticorena, B., Diallo, A., and Ndiaye, T.: Climatology of aerosol properties and clear-sky shortwave radiative effects using Lidar and Sun photometer observations in the Dakar site, Journal of Geophysical Research: Atmospheres, 121, 6489-6510, https://doi.org/10.1002/2015JD024588, https://agupubs.onlinelibrary.wiley.com/ doi/abs/10.1002/2015JD024588, 2016.

660 Myhre, G., Berglen, T. F., Johnsrud, M., Hoyle, C., Berntsen, T. K., Christopher, S., Fahey, D., Isaksen, I. S., Jones, T., Kahn, R., et al.: Modelled radiative forcing of the direct aerosol effect with multi-observation evaluation, Atmospheric Chemistry and Physics, 9, 13651392, 2009.

Neubauer, D., Ferrachat, S., Drian, S.-L., Stier, P., Partridge, D. G., Tegen, I., Bey, I., Stanelle, T., Kokkola, H., Lohmann, U., et al.: The global aerosol-climate model ECHAM6. 3-HAM2. 3-Part 2: Cloud evaluation, aerosol radiative forcing and climate sensitivity, Geoscientific Model Development Discussions, 2019.

Norris, J. R. and Wild, M.: Trends in aerosol radiative effects over Europe inferred from observed cloud cover, solar "dimming," and solar "brightening”, Journal of Geophysical Research: Atmospheres, 112, 2007.

Ogunjobi, K., Ajayi, V., Balogun, I., Omotosho, J., and He, Z.: The synoptic and optical characteristics of the harmattan dust spells over Nigeria, Theoretical and Applied Climatology, 93, 91-105, 2008.

Olivié, D. et al.: in preparation.

O'neill, N., Eck, T., Smirnov, A., Holben, B., and Thulasiraman, S.: Spectral discrimination of coarse and fine mode optical depth, Journal of Geophysical Research: Atmospheres, 108, 2003.

Pandolfi, M., Alados-Arboledas, L., Alastuey, A., Andrade, M., Angelov, C., Artiñano, B., Backman, J., Baltensperger, U., Bonasoni, P., Bukowiecki, N., et al.: A European aerosol phenomenology-6: scattering properties of atmospheric aerosol particles from 28 ACTRIS sites, Atmospheric Chemistry and Physics, 18, 7877-7911, 2018.

Peñuelas, J. and Staudt, M.: BVOCs and global change, Trends in plant science, 15, 133-144, 2010.

Pöschl, U.: Atmospheric aerosols: composition, transformation, climate and health effects, Angewandte Chemie International Edition, 44, 7520-7540, 2005.

Ramachandran, S., Kedia, S., and Srivastava, R.: Aerosol optical depth trends over different regions of India, Atmospheric Environment, 49, $338-347,2012$. 
Rap, A., Scott, C. E., Spracklen, D. V., Bellouin, N., Forster, P. M., Carslaw, K. S., Schmidt, A., and Mann, G.: Natural aerosol direct and indirect radiative effects, Geophysical Research Letters, 40, 3297-3301, 2013.

Schulz, M., de Leeuw, G., and Balkanski, Y.: Sea-salt aerosol source functions and emissions, in: Emissions of Atmospheric Trace Compounds, pp. 333-359, Springer, 2004.

Schulz, M., Textor, C., Kinne, S., Balkanski, Y., Bauer, S., Berntsen, T., Berglen, T., Boucher, O., Dentener, F., Guibert, S., et al.: Radiative forcing by aerosols as derived from the AeroCom present-day and pre-industrial simulations, Atmospheric Chemistry and Physics, 6 , 5225-5246, 2006.

Schutgens, N., Tsyro, S., Gryspeerdt, E., Goto, D., Weigum, N., Schulz, M., and Stier, P.: On the spatio-temporal representativeness of observations, Atmospheric Chemistry and Physics Discussions, 2017.

Schutgens, N. A.: Site representativity of AERONET and GAW remotely sensed AOT and AAOT observations, Atmos. Chem. Phys. Discuss., https://doi. org/10.5194/acp-2019-767, in review, 2019.

Seland, O. et al.: in preparation.

Smirnov, A., Holben, B., Eck, T., Dubovik, O., and Slutsker, I.: Cloud-screening and quality control algorithms for the AERONET database, Remote sensing of environment, 73, 337-349, 2000.

Smirnov, A., Holben, B., Lyapustin, A., Slutsker, I., and Eck, T.: AERONET processing algorithms refinement, in: AERONET Workshop, El Arenosillo, Spain, pp. 10-14, 2004.

Stocker, T.: Climate change 2013: the physical science basis: Working Group I contribution to the Fifth assessment report of the Intergovernmental Panel on Climate Change, Cambridge University Press, 2014.

Streets, D. G., Wu, Y., and Chin, M.: Two-decadal aerosol trends as a likely explanation of the global dimming/brightening transition, Geophysical Research Letters, 33, 2006.

Streets, D. G., Yu, C., Wu, Y., Chin, M., Zhao, Z., Hayasaka, T., and Shi, G.: Aerosol trends over China, 1980-2000, Atmospheric Research, 88, 174-182, 2008.

Streets, D. G., Yan, F., Chin, M., Diehl, T., Mahowald, N., Schultz, M., Wild, M., Wu, Y., and Yu, C.: Anthropogenic and natural contributions to regional trends in aerosol optical depth, 1980-2006, Journal of Geophysical Research: Atmospheres, 114, 2009.

Swart, N. C., Cole, J. N. S., Kharin, V. V., Lazare, M., Scinocca, J. F., Gillett, N. P., Anstey, J., Arora, V., Christian, J. R., Hanna, S., Jiao, Y., Lee, W. G., Majaess, F., Saenko, O. A., Seiler, C., Seinen, C., Shao, A., Sigmond, M., Solheim, L., von Salzen, K., Yang, D., and Winter, B.: The Canadian Earth System Model version 5 (CanESM5.0.3), Geoscientific Model Development, 12, 4823-4873, https://doi.org/10.5194/gmd-12-4823-2019, https://www.geosci-model-dev.net/12/4823/2019/, 2019.

Takemura, T., Okamoto, H., Maruyama, Y., Numaguti, A., Higurashi, A., and Nakajima, T.: Global three-dimensional simulation of aerosol optical thickness distribution of various origins, Journal of Geophysical Research: Atmospheres, 105, 17 853-17 873, 2000.

Takemura, T., Nakajima, T., Dubovik, O., Holben, B. N., and Kinne, S.: Single-scattering albedo and radiative forcing of various aerosol species with a global three-dimensional model, Journal of Climate, 15, 333-352, 2002.

Takemura, T., Nozawa, T., Emori, S., Nakajima, T. Y., and Nakajima, T.: Simulation of climate response to aerosol direct and indirect effects with aerosol transport-radiation model, Journal of Geophysical Research: Atmospheres, 110, 2005.

715 Tegen, I., Neubauer, D., Ferrachat, S., Drian, S.-L., Bey, I., Schutgens, N., Stier, P., Watson-Parris, D., Stanelle, T., Schmidt, H., et al.: The global aerosol-climate model ECHAM6. 3-HAM2. 3-Part 1: Aerosol evaluation, Geoscientific Model Development, 12, 1643-1677, 2019. 
Tilmes, S., Hodzic, A., Emmons, L. K., Mills, M. J., and Gettelman, A.and Kinnison, D. E. P. M. L. J.-F. V. F. S. M. J. P. C. J. J. L. X.: Climate forcing and trends of organic aerosols in the Community Earth System Model (CESM2), Journal of Advances in Modeling Earth Systems, 2019.

Tørseth, K., Aas, W., Breivik, K., Fjæraa, A. M., Fiebig, M., Hjellbrekke, A. G., Lund Myhre, C., Solberg, S., and Yttri, K. E.: Introduction to the European Monitoring and Evaluation Programme (EMEP) and observed atmospheric composition change during 1972ndash;2009, Atmospheric Chemistry and Physics, 12, 5447-5481, https://doi.org/10.5194/acp-12-5447-2012, 2012.

Turnock, S., Butt, E., Richardson, T., Mann, G., Reddington, C., Forster, P., Haywood, J., Crippa, M., Janssens-Maenhout, G., Johnson, C., et al.: The impact of European legislative and technology measures to reduce air pollutants on air quality, human health and climate, Environmental Research Letters, 11, 024 010, 2016.

Wang, R., Andrews, E., Balkanski, Y., Boucher, O., Myhre, G., Samset, B. H., Schulz, M., Schuster, G. L., Valari, M., and Tao, S.: Spatial Representativeness Error in the Ground-Level Observation Networks for Black Carbon Radiation Absorption, Geophysical Research Letters, 45, 2106-2114, https://doi.org/10.1002/2017GL076817, https://agupubs.onlinelibrary.wiley.com/doi/abs/10.1002/2017GL076817, 2018.

Wang, Z., Zhang, H., and Lu, P.: Improvement of cloud microphysics in the aerosol-climate model BCC_AGCM2. 0.1 _CUACE/Aero, evaluation against observations, and updated aerosol indirect effect, Journal of Geophysical Research: Atmospheres, 119, 8400-8417, 2014.

Werth, D. and Avissar, R.: The local and global effects of Amazon deforestation, Journal of Geophysical Research: Atmospheres, 107, LBA-55, 2002.

White, W. H., Trzepla, K., Hyslop, N. P., and Schichtel, B. A.: A critical review of filter transmittance measurements for aerosol light absorption, and de novo calibration for a decade of monitoring on PTFE membranes, Aerosol Science and Technology, 50, 984-1002, https://doi.org/10.1080/02786826.2016.1211615, 2016.

Yoon, J., von Hoyningen-Huene, W., Kokhanovsky, A., Vountas, M., and Burrows, J.: Trend analysis of aerosol optical thickness and Ångström exponent derived from the global AERONET spectral observations, Atmos. Meas. Tech, 5, 1271-1299, 2012.

Yu, H., Chin, M., Yuan, T., Bian, H., Remer, L. A., Prospero, J. M., Omar, A., Winker, D., Yang, Y., Zhang, Y., et al.: The fertilizing role of African dust in the Amazon rainforest: A first multiyear assessment based on data from Cloud-Aerosol Lidar and Infrared Pathfinder Satellite Observations, Geophysical Research Letters, 42, 1984-1991, 2015.

Zhang, H., Wang, Z., Wang, Z., Liu, Q., Gong, S., Zhang, X., Shen, Z., Lu, P., Wei, X., Che, H., et al.: Simulation of direct radiative forcing of aerosols and their effects on East Asian climate using an interactive AGCM-aerosol coupled system, Climate Dynamics, 38, 1675-1693, 2012.

Zhang, H., Jing, X., and Li, J.: Application and evaluation of a new radiation code under McICA scheme in BCC_AGCM2. 0.1, Geoscientific Model Development, 7, 737, 2014.

Zhang, J. and Reid, J.: A decadal regional and global trend analysis of the aerosol optical depth using a data-assimilation grade over-water MODIS and Level 2 MISR aerosol products, Atmospheric Chemistry and Physics, 10, 10949-10 963, 2010.

Zhang, Q., Streets, D. G., Carmichael, G. R., He, K., Huo, H., Kannari, A., Klimont, Z., Park, I., Reddy, S., Fu, J., et al.: Asian emissions in 2006 for the NASA INTEX-B mission, Atmospheric Chemistry and Physics, 9, 5131-5153, 2009.

Zhao, M., Golaz, J.-C., Held, I. M., Guo, H., Balaji, V., Benson, R., Chen, J.-H., Chen, X., Donner, L., Dunne, J., et al.: The GFDL global atmosphere and land model AM4. 0/LM4. 0: 2. Model description, sensitivity studies, and tuning strategies, Journal of Advances in Modeling Earth Systems, 10, 735-769, 2018a. 
https://doi.org/10.5194/acp-2019-1203

Preprint. Discussion started: 13 January 2020

(C) Author(s) 2020. CC BY 4.0 License.

(c) (1)

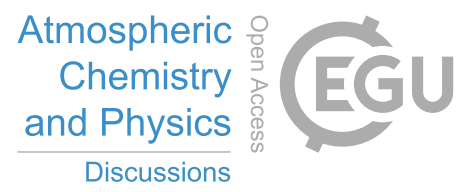

Zhao, M., Golaz, J.-C., Held, I. M., Guo, H., Balaji, V., Benson, R., Chen, J.-H., Chen, X., Donner, L., Dunne, J., et al.: The GFDL global atmosphere and land model AM4. 0/LM4. 0: 1. Simulation characteristics with prescribed SSTs, Journal of Advances in Modeling Earth Systems, 10, 691-734, 2018b. 
Table 1. List of observations and model datasets used in this study (see text for explanation).

\begin{tabular}{|c|c|c|c|}
\hline Parameter & Type & Observation networks & Models \\
\hline AOD & Column & AERONET $^{1}$ & $\begin{array}{l}\text { ECMWF-Rean; NorESM2; SPRINTARS; ECHAM- } \\
\text { HAM; GEOS; OsloCTM3; GFDL-AM4; BCC- } \\
\text { CUACE; CanESM5; CESM2; IPSL-CM6A }\end{array}$ \\
\hline $\mathrm{AOD}<1 \mu \mathrm{m}$ & Column & AERONET & $\begin{array}{l}\text { NorESM2; SPRINTARS; ECHAM-HAM; GEOS; } \\
\text { GFDL-AM4 }\end{array}$ \\
\hline $\mathrm{AE}$ & Column & AERONET & $\begin{array}{l}\text { ECMWF-Rean; NorESM2; SPRINTARS; ECHAM- } \\
\text { HAM; GEOS; OsloCTM3; GFDL-AM4 }\end{array}$ \\
\hline $\mathrm{PM}_{2.5}$ & Surface & $\mathrm{EMEP}^{2} ; \mathrm{IMPROVE}^{3}$ & $\begin{array}{l}\text { ECMWF-Rean; NorESM2; SPRINTARS; ECHAM- } \\
\text { HAM; GEOS }\end{array}$ \\
\hline$\sigma_{s p}$ & Surface & GAW-WDCA $^{7}$ (incl. IMPROVE; NOAA-FAN ${ }^{8}$; ACTRIS ${ }^{9}$; EMEP) & NorESM2; SPRINTARS \\
\hline$\sigma_{a p}$ & Surface & GAW-WDCA (incl. NOAA-FAN; ACTRIS; EMEP) & NorESM2; SPRINTARS \\
\hline
\end{tabular}

${ }^{1}$ Aerosol Robotic Network ${ }^{2}$ The European Monitoring and Evaluation Program ${ }^{3}$ Interagency Monitoring of Protected Visual Environments ${ }^{4}$ Clean Air Status and Trends Network ${ }^{5}$ The Canadian Air and Precipitation Monitoring Network ${ }^{6}$ Acid Deposition Network in East Asia ${ }^{7}$ Global Atmosphere Watch - World Data Centre for Aerosol ${ }^{8}$ National Oceanic and Atmospheric Administration Federated Aerosol Network ${ }^{9}$ Aerosol, Clouds, and Trace Gases Research Infrastructure 


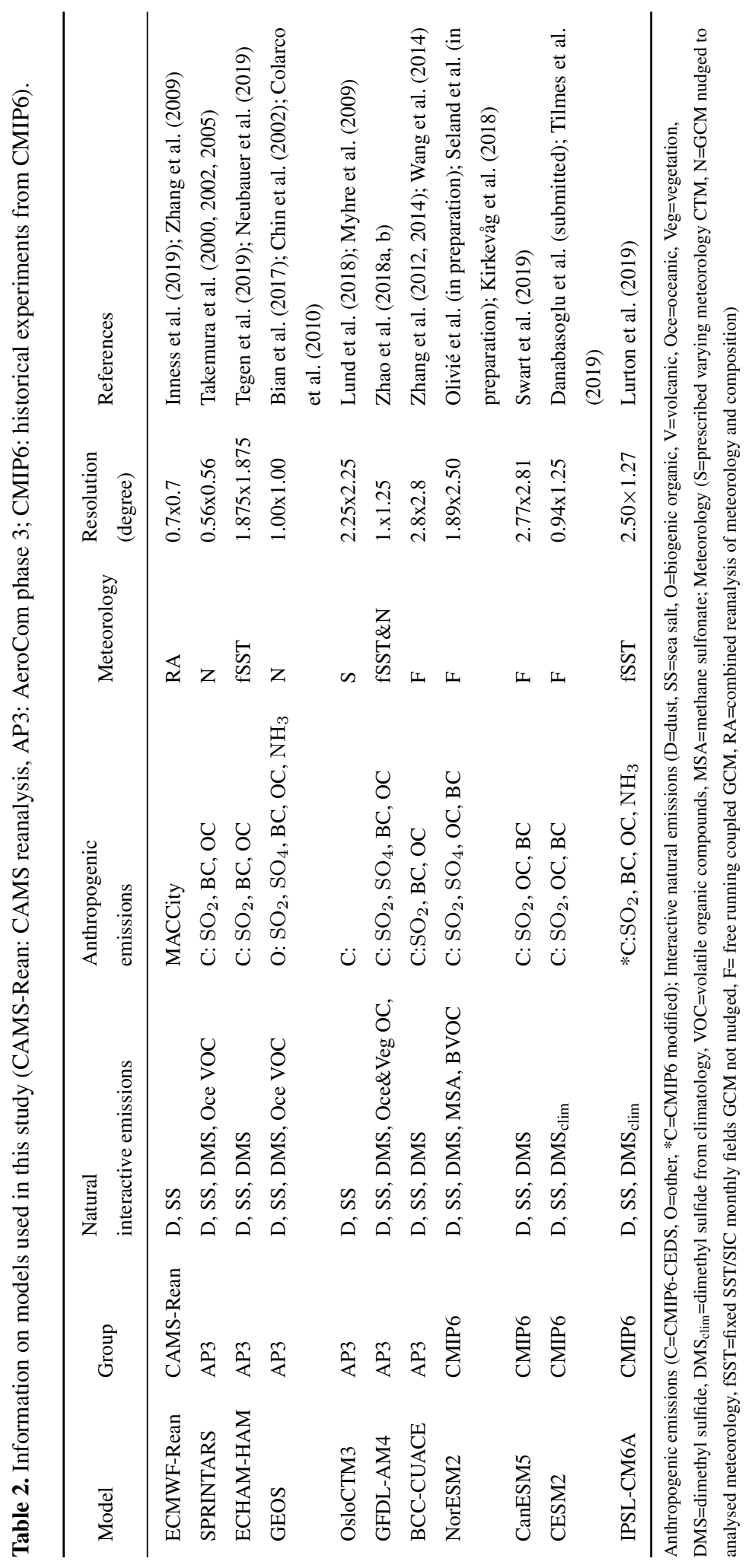


Table 3. Observational mean values for the year 2000, the reference year used for computing relative trends. Each value is extracted as the intercept of the linear trend computed in the 2000-2014 period, except for $\sigma_{s p}$ and $\sigma_{a p}$, where the trends have been computed over 2000-2018. Because the required minimum number of yearly averages was set to seven, no trend could be computed in the southern African region.

\begin{tabular}{lcccccc}
\hline & EUROPE & NAMERICA & SAMERICA & NAFRICA & ASIA & AUSTRALIA \\
\hline $\mathrm{AOD}$ & 0.17 & 0.10 & 0.15 & 0.26 & 0.35 & 0.10 \\
$\mathrm{AOD}<1 \mu \mathrm{m}$ & 0.14 & 0.08 & 0.12 & 0.11 & 0.18 & 0.05 \\
$\mathrm{AOD}>1 \mu \mathrm{m}$ & 0.03 & 0.02 & 0.03 & 0.10 & 0.11 & 0.03 \\
$\mathrm{AE}$ & 1.44 & 1.46 & 1.30 & 0.72 & 1.06 & 0.97 \\
$\mathrm{PM}_{2.5}\left(\mu \mathrm{g} \cdot \mathrm{m}^{-3}\right)$ & 12.8 & 7.3 & - & - & - & - \\
$\mathrm{PM}_{10}\left(\mu \mathrm{g} \cdot \mathrm{m}^{-3}\right)$ & 16.8 & 12.8 & - & 19.6 & - & - \\
$\mathrm{SO}_{4}\left(\mu \mathrm{g} \cdot \mathrm{m}^{-3}\right)$ & 2.01 & 1.45 & - & 2.98 & 1.97 & - \\
$\sigma_{s p}\left(\mathrm{Mm}^{-1}\right)$ & 33.2 & 25.0 & - & - & - & - \\
$\sigma_{a p}\left(\mathrm{Mm}^{-1}\right)$ & 9.7 & 2.7 & - & - & - & - \\
\hline
\end{tabular}

Table 4. Global means and trends of aerosol parameters using NorESM2 model data. The value in parenthesis is obtained by aggregating only grid-points where observation stations are located while using the complete model time series. The relative trends are calculated by averaging the absolute trends within the considered grid-points and normalizing it to the global mean for the year 2000.

\begin{tabular}{lcc}
\hline & Mean $_{2000}$ & Trend (\%/yr) \\
\hline $\mathrm{AOD}$ & $(0.16) 0.14$ & $(+0.1)+0.2$ \\
$\mathrm{AOD}<1 \mu \mathrm{m}$ & $(0.09) 0.05$ & $(+0.4)+0.6$ \\
$\mathrm{AOD}>1 \mu \mathrm{m}$ & $(0.06) 0.09$ & $(-0.2)+0.1$ \\
$\mathrm{AE}$ & $(0.78) 0.43$ & $(+0.2)+0.3$ \\
$\mathrm{PM}_{2.5}\left(\mu \mathrm{g} . \mathrm{m}^{-3}\right)$ & $(12.4) 9.1$ & $(+0.2)+0.2$ \\
$\mathrm{PM}_{10}\left(\mu \mathrm{g} \cdot \mathrm{m}^{-3}\right)$ & $(19.3) 18.7$ & $(+0.1)+0.1$ \\
$\mathrm{SO}_{4}\left(\mu \mathrm{g} \cdot \mathrm{m}^{-3}\right)$ & $(2.33) 0.64$ & $(-1.1)+0.4$ \\
$\sigma_{s p}\left(\mathrm{Mm}^{-1}\right)$ & $(28.0) 21.2$ & $(+0.3)+0.2$ \\
$\sigma_{a p}\left(\mathrm{Mm}^{-1}\right)$ & $(3.1) 0.9$ & $(+1.8)+1.5$ \\
\hline & &
\end{tabular}


https://doi.org/10.5194/acp-2019-1203

Preprint. Discussion started: 13 January 2020

(C) Author(s) 2020. CC BY 4.0 License.

(c) (1)

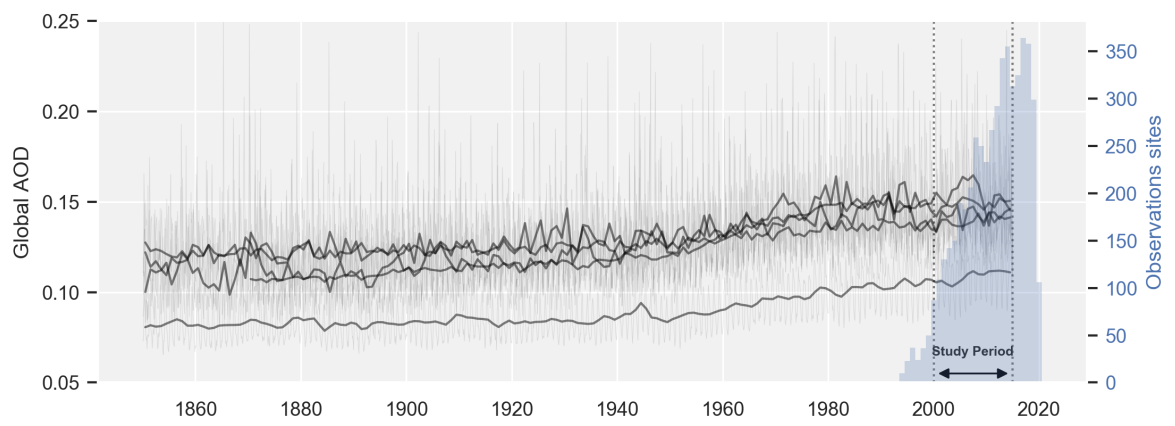

Figure 1. Global AOD computed from model historical runs (OsloCTM3, GFDL-AM4, CanESM5, CESM2, IPSL-CM6A, ECHAM-HAM) at monthly (gray lines) and yearly resolutions (black lines), overlayed with the number of active observation sites in the sun photometer network AERONET. 
https://doi.org/10.5194/acp-2019-1203

Preprint. Discussion started: 13 January 2020

(c) Author(s) 2020. CC BY 4.0 License.

(c) (1)

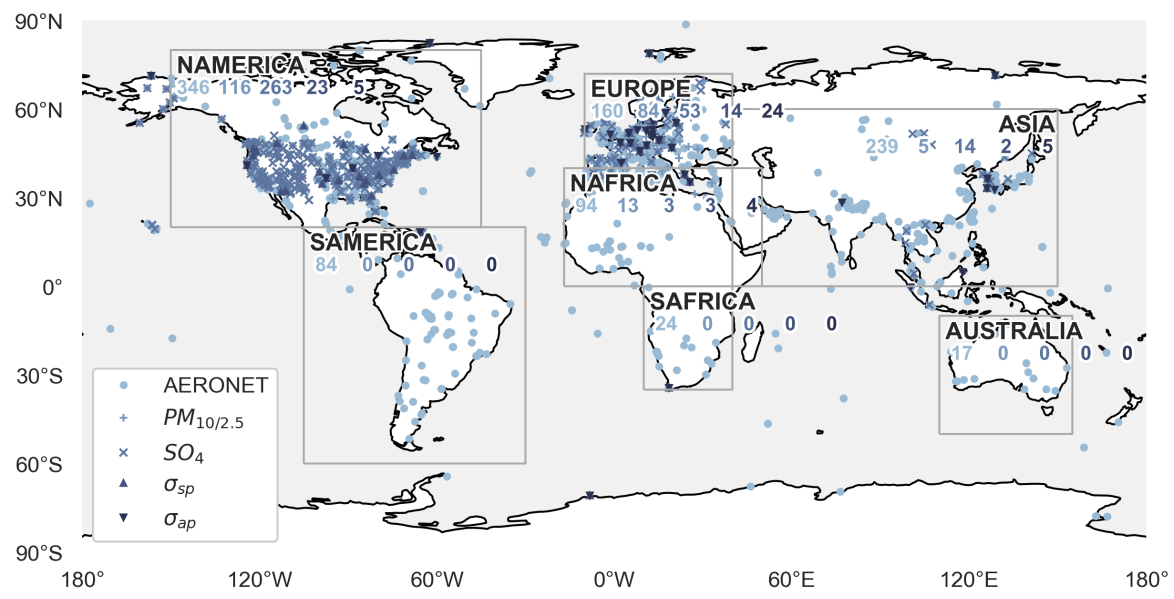

Figure 2. Distribution of the observations within the different regions considered in this study. The numbers reported within each region correspond to the maximum number of stations given for the observation networks corresponding to the five observation types found in the legend. 


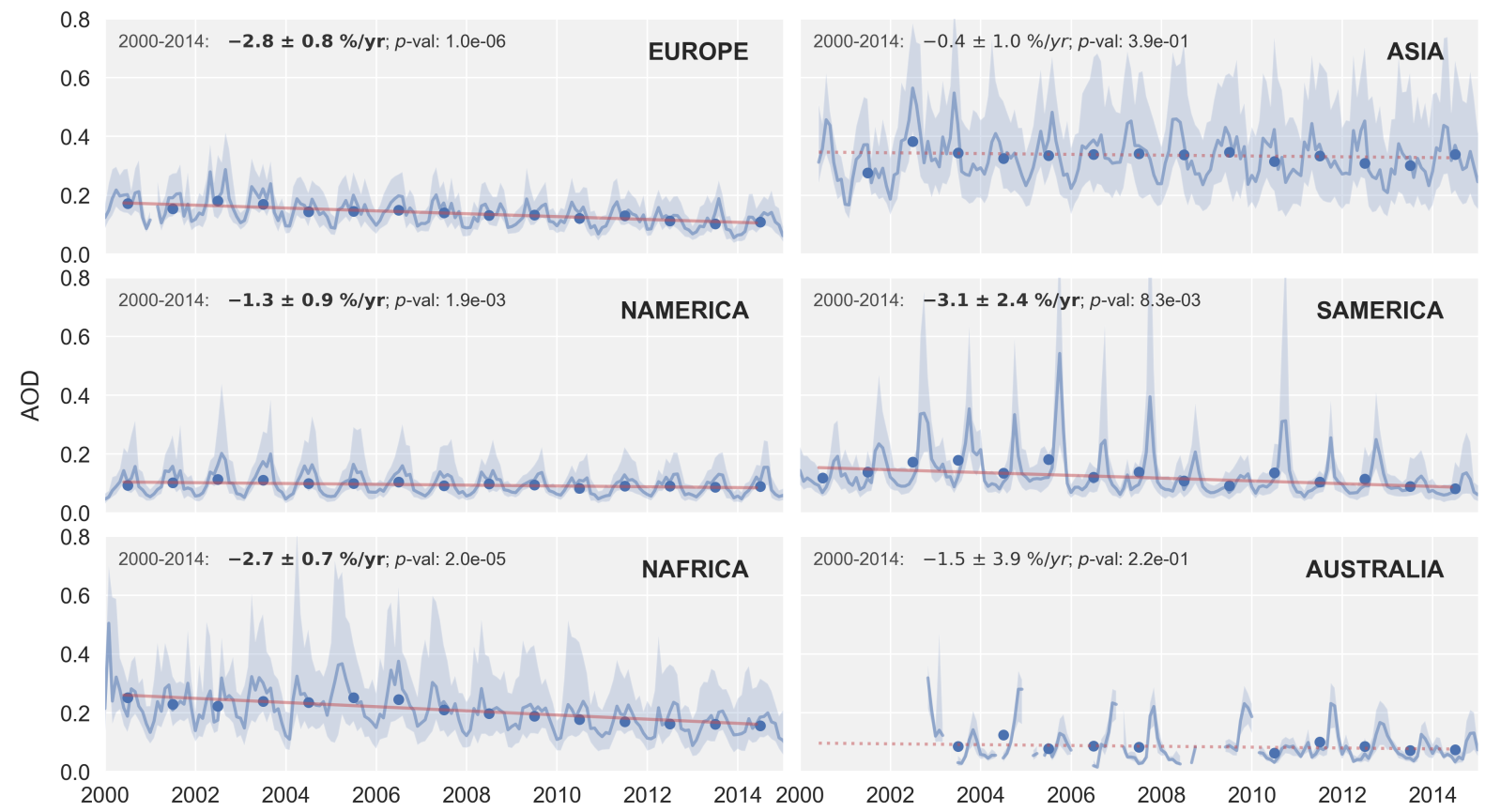

Figure 3. Regional time series of AOD. The dark blue line corresponds to the median and the light blue envelope is bound by the first and third quartiles of all valid points at the corresponding month, respectively. The blue dots correspond to the yearly averages which are used to compute the linear trend. The latter is displayed as a continuous line when the trend is significant and as a dashed line when it is not. Trend values, an error estimate and significance value are given in the figure. 

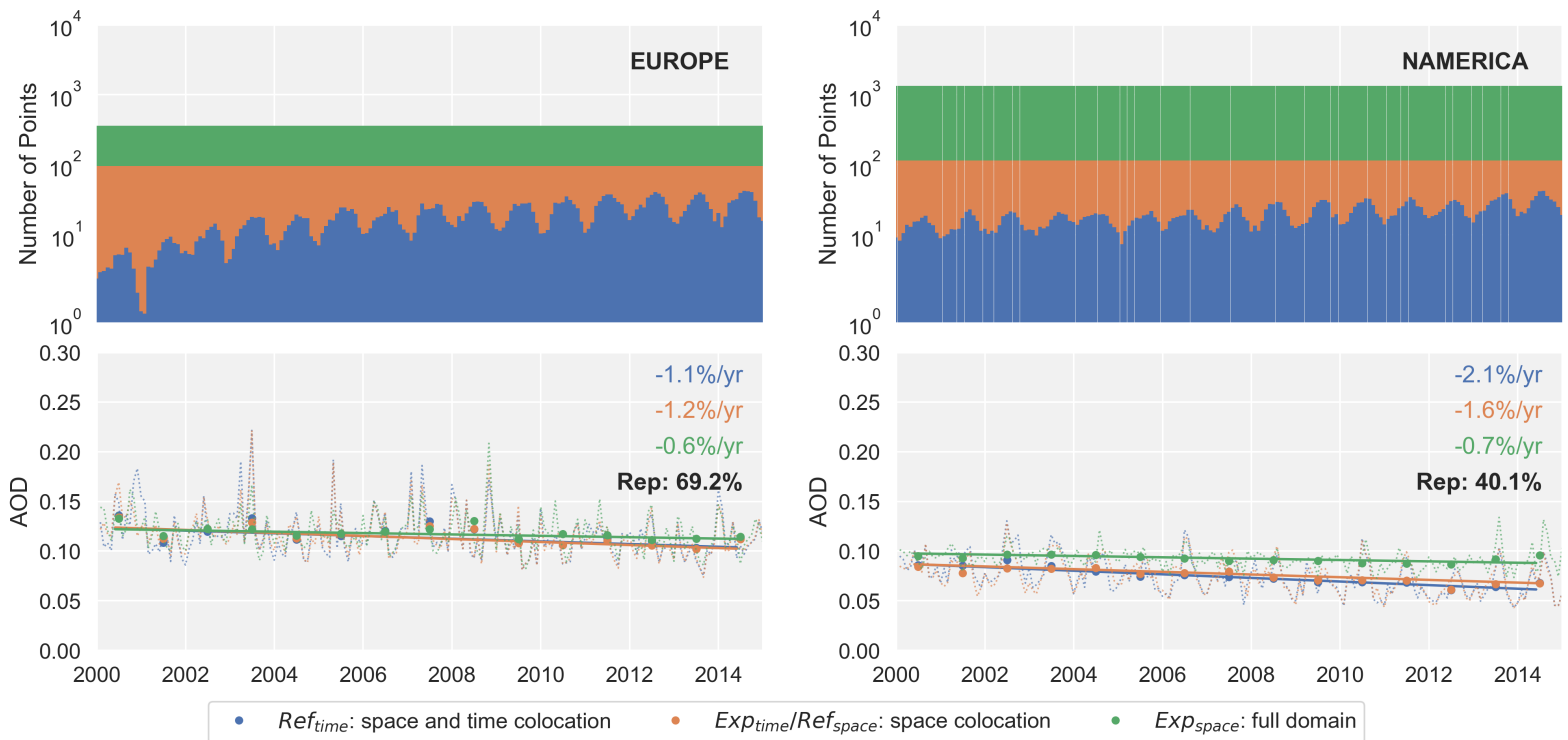

Figure 4. Three regional AOD time series and respectived trends, constructed from model data for the investigation of representativeness of the observational data. The upper figures correspond to the number of points used to compute the regional time series for the three different datasets. The lower figures show the time series, the trends, and the resulting representativity value (black, bold). Re $f_{\text {time }}$ corresponds to the model output collocated in space and time to the available observations. Exptime $/ R e f_{\text {space }}$ corresponds to the model output collocated in space to the stations providing measurements, using the complete time series from 2000 to 2014. Exp space corresponds to the model output in the whole geographic region (see 2) without any collocation to the observations. 
https://doi.org/10.5194/acp-2019-1203

Preprint. Discussion started: 13 January 2020

(c) Author(s) 2020. CC BY 4.0 License.

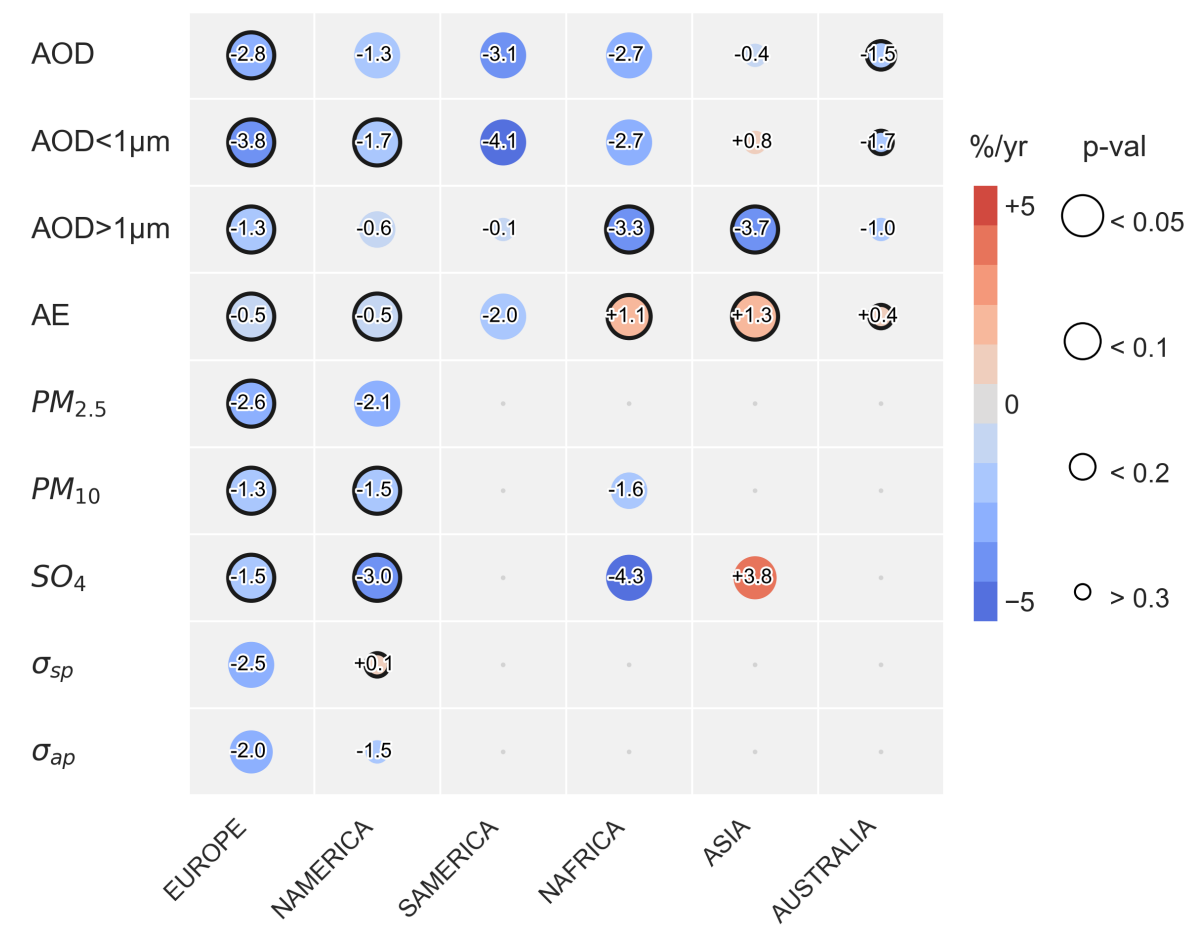

Figure 5. Regional trends of the aerosol properties computed with the observation datasets. The color of the circles corresponds to the slope, while the radius indicates the $\mathrm{p}$-value. The largest circles represent the trends significant with a confidence of $95 \%$. The circles bordered with a black line indicate the trends associated with a representativity greater than $50 \%$. 

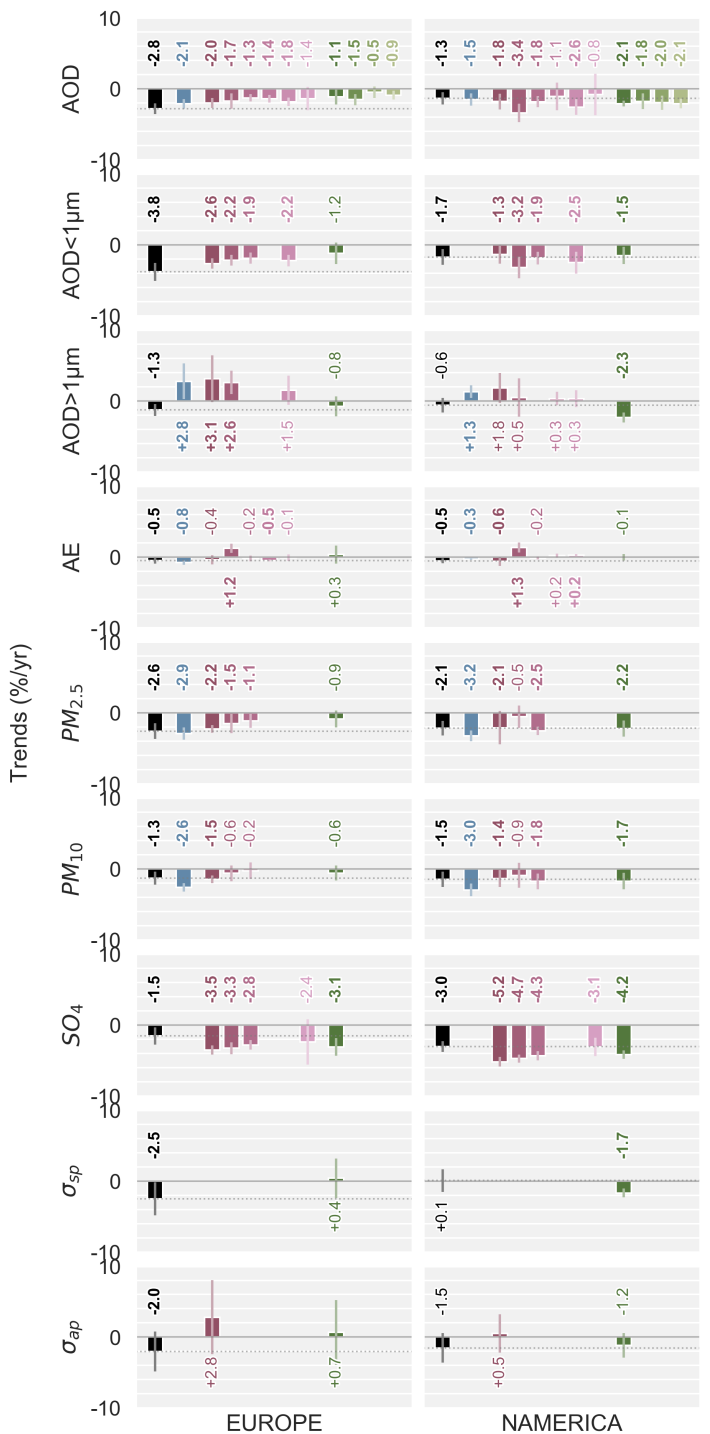

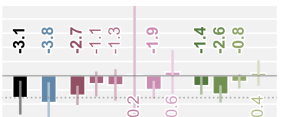

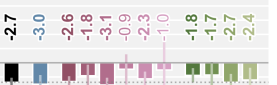

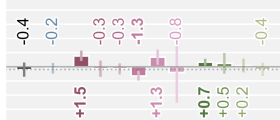

$\overline{\dot{4}}$
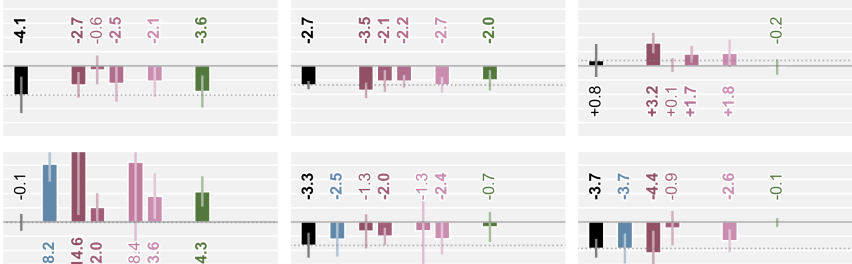

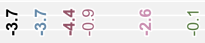

n $|1| \|^{+}$

ำ

$\boldsymbol{4}$ -
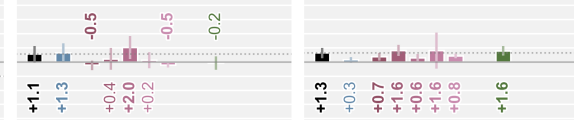

兴

Figure 6. Regional trends of the aerosol properties computed with observations and models collocated in space and time to the observations. The error bars correspond to the uncertainty of the trend as calculated using both the uncertainty on the Theil-Sen slope and the residuals. The bold font indicates that the trends are significant with an expectancy of $95 \%(\mathrm{p}$-val< $<0.05)$. 
https://doi.org/10.5194/acp-2019-1203

Preprint. Discussion started: 13 January 2020

(c) Author(s) 2020. CC BY 4.0 License.

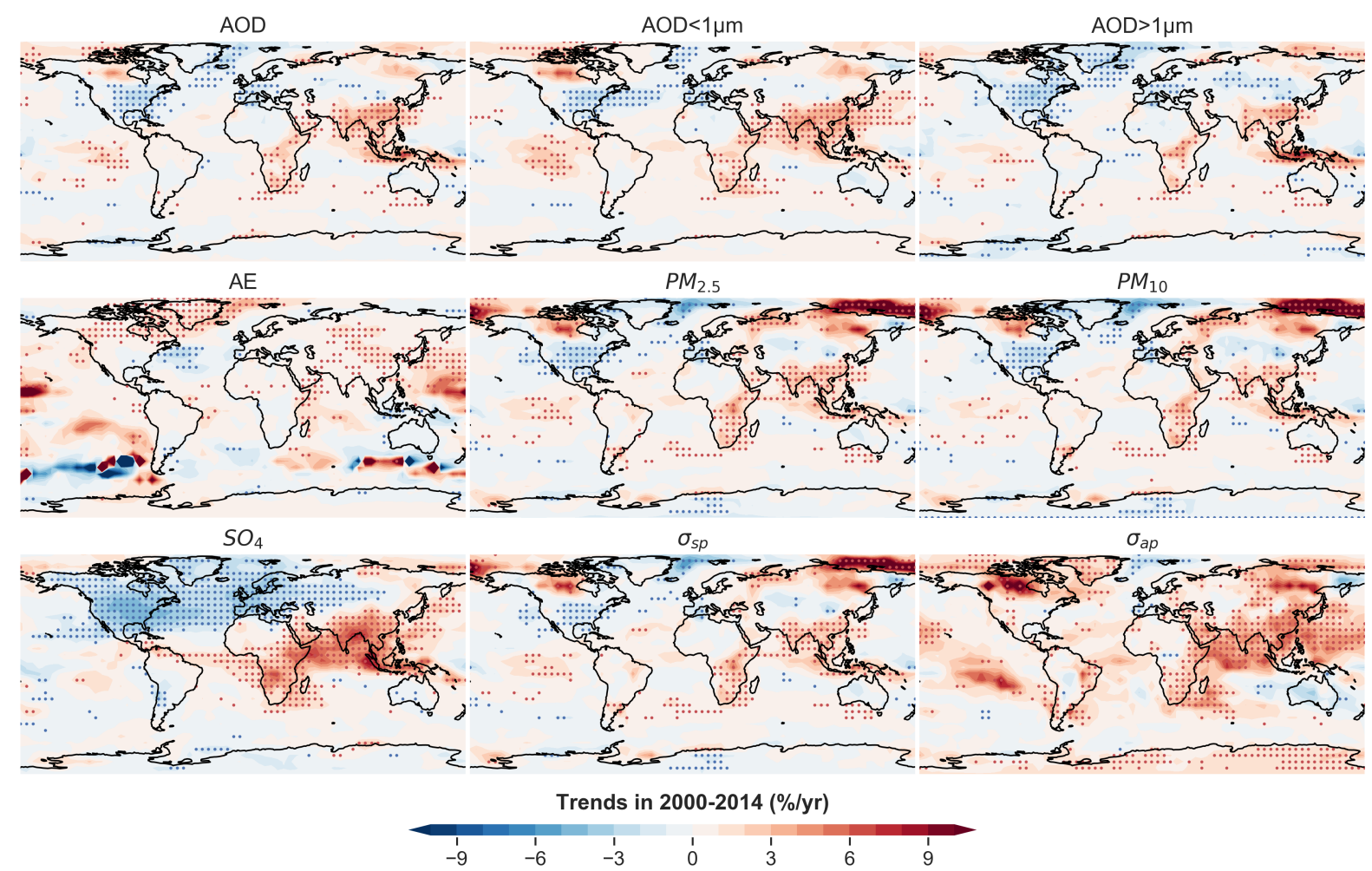

Figure 7. Global trends of aerosol properties using NorESM2 data regridded at a $5 \times 5$ degrees resolution. The blue and red dots dots indicate respectively significant negative and positive trends. 
https://doi.org/10.5194/acp-2019-1203

Preprint. Discussion started: 13 January 2020

(c) Author(s) 2020. CC BY 4.0 License.
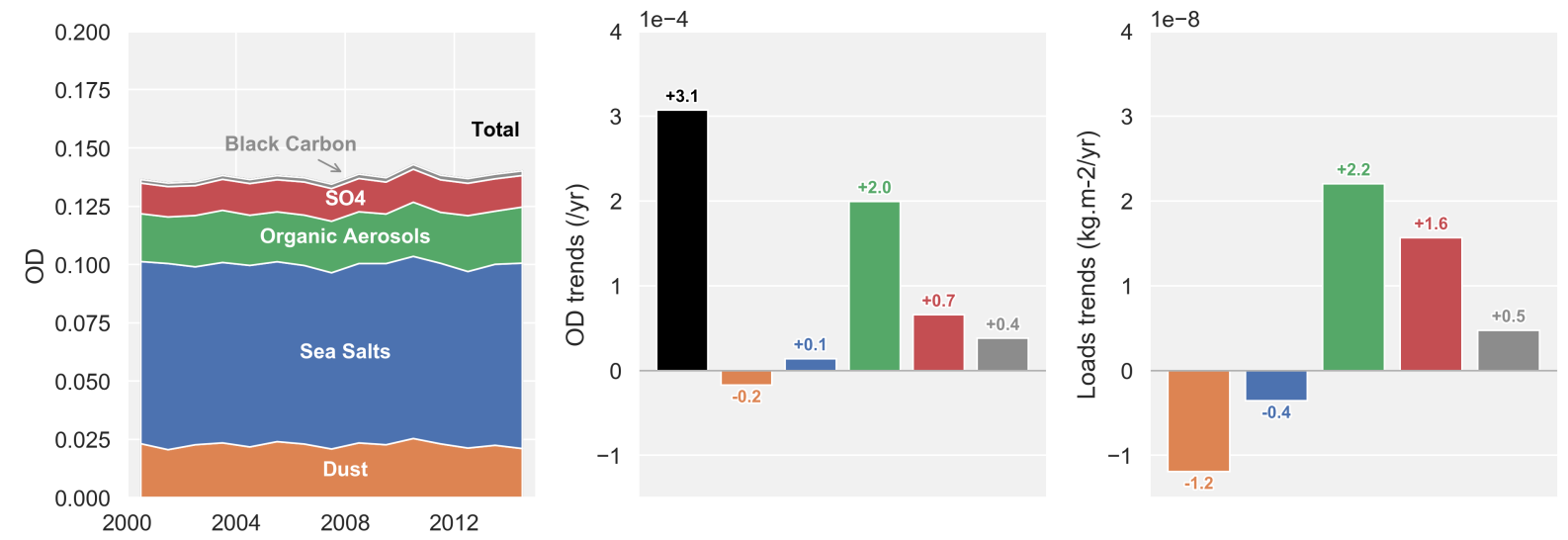

Figure 8. Absolute trends in OD and emissions of the main aerosol species computed with NorESM2. The y-axis of the trends in OD and the emissions is given according to the power of 10 indicated at the top left corner of each of the subplots. 